\title{
Secular variations in the carbonate chemistry of the oceans over the Cenozoic
}

\author{
Bernard P. Boudreau $^{\mathrm{a}, *}$, Jack J. Middelburg ${ }^{\mathrm{b}}$, Appy Sluijs ${ }^{\mathrm{b}}$, Robin van der Ploeg ${ }^{\mathrm{b}}$ \\ a Department of Oceanography, Dalhousie University, Halifax, Nova Scotia B3H4J1, Canada \\ ${ }^{\mathrm{b}}$ Department of Earth Sciences, Faculty of Geosciences, Utrecht University, Utrecht, Netherlands
}

\section{A R T I C L E I N F O}

\section{Article history:}

Received 29 April 2018

Received in revised form 7 January 2019

Accepted 3 February 2019

Available online 20 February 2019

Editor: J. Adkins

\section{Keywords:}

Cenozoic Era

carbonate chemistry

inverse model

seawater $\mathrm{pH}$ record

atmospheric $\mathrm{pCO}_{2}$ record

\begin{abstract}
A B S T R A C T
Oceanic carbonate chemistry during the Cenozoic has affected the climatology, ecology, and marine geology of our planet; yet, we have limited means to know the evolution of that chemistry, due to a lack of preserved and unaltered seawater samples and a continuing paucity of proxies. Modeling is often used to address this problem; here, we offer a simple, data-driven, secular timescale, inverse model for the mean, Cenozoic, carbonate chemistry of the oceans. Inputs for the model include carbonate compensation depth (CCD), $\mathrm{CaCO}_{3}$ burial, seawater temperature, atmospheric $\mathrm{CO}_{2}$ and carbonate ion records, as well as a simple set of original, but justified, assumptions. The model retrodicts the total dissolved inorganic carbon (DIC), carbonate alkalinity (CAlk), and $\mathrm{pH}$ of the surface and deep waters of the ocean. The retrodicted DIC and CAlk records do not indicate any unusually elevated values in the early Cenozoic, as found in some past studies. If the CCD record from Lyle et al. (2008) is employed, the changes in DIC and CAlk appear entirely related to changes in the alkalinity input to the pelagic oceans and atmospheric $\mathrm{CO}_{2}$; however, with the CCD from Pälike et al. (2012), the increases in DIC and CAlk during the last $15 \mathrm{Ma}$ reflect the effects of ocean cooling. Using either CCD-record, our model provides consistent retrodictions of the available pH record. Our results are not consistent with many past modeling assumptions, such as constancy of alkalinity in surface waters, or the ratio of shallow and deep carbonate ion concentrations. Finally, we use our results to provide new estimates of atmospheric $\mathrm{CO}_{2}$ based on Boron isotopes and find significantly lower $\mathrm{CO}_{2}$ values in the early Cenozoic than previous values.
\end{abstract}

(C) 2019 Elsevier B.V. All rights reserved.

\section{Introduction}

Understanding how the carbonate chemistry of the oceans has evolved on a timescale of 100 million years constitutes a central theme of paleoceanographic research. The nature of that evolution is imperative in comprehending changes in the deposition and preservation of biogenic sediments, past shifts in marine biological species (including extinctions), variations in carbon isotopic records found in sediments, and the history of the $\mathrm{CO}_{2}$ content of the atmosphere.

The most coveted information of this type is arguably the carbonate system concentrations of past oceans. There exist unfortunately no unaltered samples of ancient seawater (e.g., as inclusions) that can be analyzed for carbonate system components, i.e., dissolved carbon dioxide $\left(\mathrm{CO}_{2}\right)$, bicarbonate ion $\left(\mathrm{HCO}_{3}{ }^{-}\right)$and carbonate ion $\left(\mathrm{CO}_{3}{ }^{2-}\right)$, nor their analytical surrogates, i.e., titration total alkalinity and total dissolved inorganic carbon $\left(\mathrm{DIC}=\mathrm{CO}_{2}\right.$

\footnotetext{
* Corresponding author.

E-mail address: bernie.boudreau@dal.ca (B.P. Boudreau).
}

$\left.+\mathrm{HCO}_{3}{ }^{-}+\mathrm{CO}_{3}{ }^{2-}\right)$. Although proxies for some carbonate components have been advanced, these proposals are either confounded by other factors (e.g., $\mathrm{B} / \mathrm{Ca}$ proxy for $\mathrm{CO}_{3}{ }^{2-}$, Yu and Elderfield, 2007), or cannot be applied on secular timescales, e.g., the $\delta^{7} \mathrm{Li}$ proxy for total dissolved inorganic carbon (Vigier et al., 2015) because of long-term changes in $\delta^{7} \mathrm{Li}$ (Misra and Froelich, 2012). $\mathrm{pH}$ now has a proxy $\left(\delta^{11} \mathrm{~B}\right)$, and that does place some constraints on the carbonate system (e.g., Spivak et al., 1993; Palmer et al., 1998; Palmer and Pearson, 2003; Yu and Elderfield, 2007; Hönisch et al., 2009; Anagnostou et al., 2016).

This lack of data has inspired the marine and geochemical modeling communities to formulate and solve (long-term) mathematical models that aim, as part of their results, to provide some measure of the carbonate chemistry of the oceans. Initial versions of such models treated the oceans simply as a single reservoir in a large multi-reservoir representation of the carbon cycle of the earth as it evolved through time, e.g., Berner et al. (1983). Any retrodictions, i.e. predictions of the past, of the carbonate chemistry of the oceans from such models, including their similarly constructed progeny (e.g., Mackenzie et al., 1993; Wallmann, 2001; Berner, 2006; Arvidson et al., 2006), only provide gross averages, at 
best, which limits their utility for many paleoceanographic applications. The dichotomy in the dissolved carbonate chemistry between the surface and the deep waters of the oceans, and the differing processes that create this situation, are fundamental to credible retrodiction. Conversely, the lateral gradients in the oceans are far smaller and can often be ignored to a first approximation, as discussed below.

Paleoceanographic models that have the essential vertical resolution have appeared over the past $15 \mathrm{yr}$, either as multi-box models of the ocean, e.g., Keir (1988), Caldeira and Rampino (1993), Ridgwell et al. (2003), Zeebe and Zachos (2007), Zeebe (2012), Omta et al. (2013), and Caves et al. (2016), as spatially resolved intermediate complexity models, e.g., Maier-Reimer (1993), Ridgwell and Hargreaves (2007) and the review by Hülse et al. (2017), and even in fully coupled GCMs, e.g., Winguth and Winguth (2012) and Heinze and Ilyina (2015).

As with all conservation models involving time stepping, i.e., either ordinary or partial differential equations, such models face one enormous hurdle: what initial conditions do you set for the model? The problem here is that the initial carbonate chemistry is no more known than that chemistry at any later time, except for the present of course. The models are unstable to march backwards in time, so that cannot be done to eliminate this problem. To make matters worse, most (if not all) of these models are underdetermined, i.e., more unknowns, both variables and parameters, than equations, and additional data or assumptions must be introduced. Adding related variables, like stable carbon isotope ratios $\left(\delta^{13} \mathrm{C}\right)$, might alleviate some of the problems, but usually one must introduce various new additional assumptions. Modeling the oceans of the past is not for the fainthearted.

The most commonly made assumptions are:

(1) The mean calcite saturation state of the surface oceans has remained approximately constant over the Cenozoic (Tyrrell and Zeebe, 2004; Caves et al., 2016);

(2) The ratio of the carbonate ion concentrations in the surface and deep water has remained constant (Tyrrell and Zeebe, 2004);

(3) The ratio of the export flux of organic matter (productivity) to the export flux of $\mathrm{CaCO}_{3}$ tests (calcification) is, at least, piecewise fixed (Sigman and Boyle, 2000);

(4) The alkalinity of the surface ocean is constant or has a fixed relation to salinity (Hönisch and Hemming, 2005);

(5) The depth where the export flux of $\mathrm{CaCO}_{3}$ is exactly matched by the rate of dissolution at the seafloor, i.e., the carbonate compensation depth (CCD), is the same as the depth where seawater first becomes undersaturated with respect to calcite, i.e., the saturation depth, $z_{\text {sat }}$ (Tyrrell and Zeebe, 2004; Caves et al., 2016).

Attempts have been made, e.g., Tyrrell and Zeebe (2004), to justify these assumptions based on paleoceanographic data, e.g., calcite snowline records, i.e., depth where the $\mathrm{CaCO}_{3}$ content of sediments drops effectively to zero. Some papers, e.g., Tyrrell and Zeebe (2004) and Caves et al. (2016), have also included an effort to evaluate the sensitivity of their results to likely variability associated with their assumption(s).

There is a means, however, to incorporate more paleoceanographic data into the formulation and solution of a model. Such models are inverse models sensu lato, as they use data that characterize the output of a system, e.g., burial, CCD and atmospheric $\mathrm{CO}_{2}$ records, to glean information about the inputs, the composition of the ocean, and the parameters of that system, e.g., alkalinity flux to the deep ocean, calcification rates, etc.

More than a decade ago, Tyrrell and Zeebe (2004) constructed an early form of such a model, but still needed to invoke some of the assumptions listed above. More recently, Boudreau and Luo (2017) created a more advanced example of this type of procedure. In that study, the records of the past positions of the carbonate compensation depth $\left(z_{\mathrm{cc}}\right)$ were used to infer rates of calcification and $\mathrm{CaCO}_{3}$ burial in the deep ocean on secular timescale ( $\geq 1 \mathrm{Ma}$ ). None of assumptions (1)-(5) listed above were employed in that study. In fact, only one assumption was invoked, i.e., that the shape of the $\mathrm{CaCO}_{3}$-content profile with ocean depth could be calculated simply from values of the compensation and saturation depths and the depositional rate of non-carbonate sediment (clay). Note that even that shape assumption is not necessary if the $\mathrm{CaCO}_{3}$ burial and $\mathrm{CCD}$ records can be shown to be mutually consistent, as they appear to be over the past $30 \mathrm{Ma}$ (Boudreau and Luo, 2017).

Here, we present an inverse model for the mean dissolved carbonate chemistry of the pelagic ocean over the Cenozoic. Our model does not try to invert a complete earth system science model, but instead the small set of equations that account for conservation of the dissolved carbonate species of a mean pelagic ocean, surface and deep; consequently, only carbonate alkalinity $\left(\mathrm{CAlk}=\mathrm{HCO}_{3}{ }^{-}+2 \mathrm{CO}_{3}{ }^{2-}\right.$ ), total dissolved inorganic carbon (DIC = $\mathrm{CO}_{2}(\mathrm{aq})+\mathrm{HCO}_{3}{ }^{-}+\mathrm{CO}_{3}{ }^{2-}$ ), seawater $\mathrm{pH}$, and atmospheric $\mathrm{CO}_{2}$ are addressed and the processes that directly influence them.

We need to introduce our own assumptions to solve our equations, but none of those listed above. For example, we assume that all organic matter export from the surface pelagic oceans is regenerated in the deep water and not preserved in sediments. To put that assumption in context, according to Sarmiento and Gruber (2006), the present pelagic oceans export $\sim 550 \mathrm{TmolCa}^{-1}$ at $100 \mathrm{~m}$ water depth, but ultimately bury in pelagic sediments only $1.6 \mathrm{TmolCa}^{-1}$; thus, the leak through burial is only $0.3 \%$ of export. Our model predicts an export of $170 \mathrm{Tmola}^{-1}$, but at $200 \mathrm{~m}$, and burial would account for a loss of $\sim 1 \%$. These numbers explain why we set regeneration equal to export in our model; however, we demonstrate explicitly the weak influence of deep-sea carbon preservation later in our paper. Similarly, we decouple organic and inorganic carbon diagenesis in sediments, i.e., organic matter oxidation does not significantly affect pelagic $\mathrm{CaCO}_{3}$ burial, contrary to the hypothesis offered by Emerson and Bender (1981); despite wide use, little empirical evidence has accumulated that demonstrates the validity of this hypothesis, e.g., Jahnke and Jahnke (2004).

Our aims with the present contribution are (1) to provide a secular-scale estimate of the chemical conditions for the carbonate system, i.e., carbonate alkalinity, DIC and $\mathrm{pH}$, and (2) to examine if the results of our alternative model suggest that any of the assumptions in the list above are universal and independent of the model employed, so that they may safely be adopted regardless of the model. This latter point is particularly important when trying to estimate past oceanic carbonate chemistry or atmospheric $\mathrm{CO}_{2}$ levels from proxies, e.g., from Boron isotopes. Finally, we employ our results to provide new estimates of atmospheric $\mathrm{CO}_{2}$ over the Cenozoic from the Boron-isotope record.

\section{Model and inputs}

\subsection{Model specification}

Central in our approach is the surface to deep water dichotomy in their carbonate chemistries; as such, a single box model of the oceans is inadequate. However, lateral gradients, within either the surface or deep oceans, are of second order importance to the overall dynamics of the inorganic carbonate chemistry of the oceans. More specifically, while we fully realize that horizontal gradients exist in the oceans, they pale in magnitude to those in the vertical direction. For example, both CAlk and DIC change by as much as $300 \mu \mathrm{M}$ vertically over $<5 \mathrm{~km}$; horizontal gradients of 


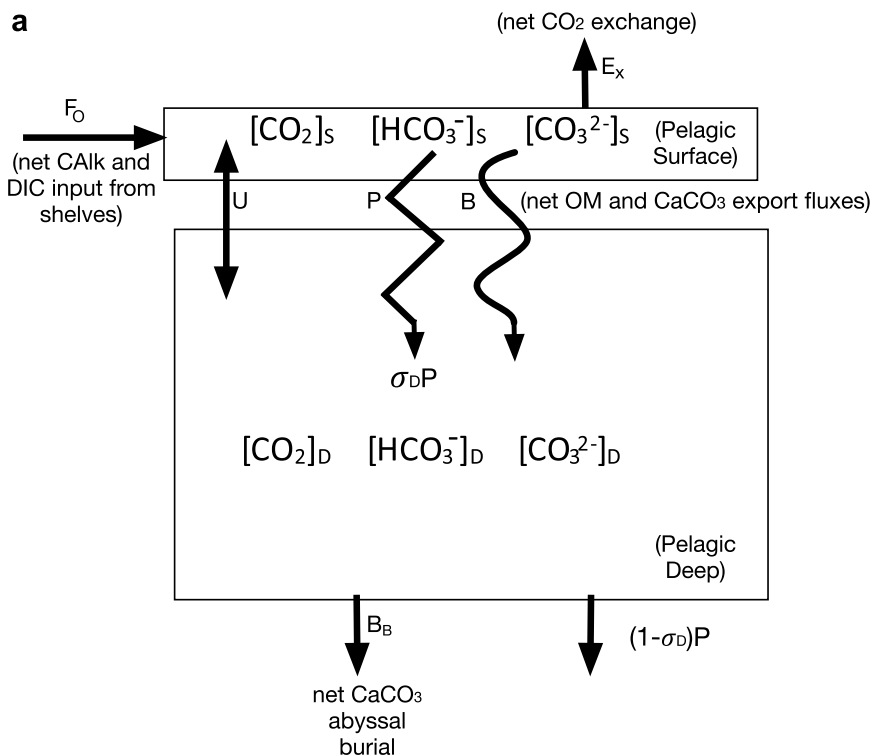

Fig. 1. a. Conceptual diagram of the two-box dissolved carbonate system model used in this paper. Terms are also defined in panel B. b. Equations describing the secular state of the dissolved carbonate system in a two-box model of the oceans. We note that $F_{0}$ in equation (1) is the net rate of alkalinity input to the pelagic oceans, i.e., the difference between the input from rivers (due to weathering) and the net rate of alkalinity removal or addition by nearshore processes, while discounting significant hydrothermal input (Berner and Berner, 2012). $F_{0}$ is a calculated quantity and not assigned. $\mathrm{HCO}_{3}{ }^{-}$is the dominant form of DIC and CAlk in ocean water (Sarmiento and Gruber, 2006); thus, $F_{\mathrm{O}}$ appears in equation (2) as a source of DIC to the pelagic ocean. We thus assume that DIC/Calk ratio of the input $F_{0}$ is one and invariant. these same variables are of the order of $200 \mu \mathrm{M}$ over $25000 \mathrm{~km}$, e.g., Sarmiento and Gruber (2006). When fully resolved, biogeochemical models are applied to the past, their predictions remain in line with these estimates, e.g., Heinze and Ilyina (2015). Consequently, unless there is a real need to resolve the horizontal changes, they can be ignored safely if the mean behavior of the oceans is the focus of the model, as it is here.

The simplest model that can capture a vertical dichotomy, while ignoring horizontal gradients, is a two-box model. One could argue that a three-box model that contains a high-latitude box for deep convection, i.e., a Harvardton-Bear model (Sarmiento and Toggweiler, 1984; Siegenthaler and Wenk, 1984; Knox and McElroy, 1984; Broecker et al., 1999; Boudreau et al., 2010) might better represent the dynamics of the ocean, but that is only on "short" timescales. On a secular timescale, i.e. $\geq 1 \mathrm{Ma}$ (Boudreau and Luo, 2017), which concerns the present paper, the high-latitude box adds nothing substantial. The transit time is too short and its volume too small to influence any of our conclusions; thus, it is left out of our model.

The dependent variables in our model are the concentrations of the dissolved carbonate species in surface and deep reservoirs. A conceptual diagram for our model is presented in Fig. 1a, and the conservation equations for these quantities for our two model boxes are displayed in Fig. 1b - the first two equations for each box are for DIC and CAlk. Our model is based on CAlk because the latter is sufficient to fully specify ocean carbonate chemistry. Our CAlk results can easily be converted into total alkalinity (TAlk) see the Supplemental Information (SI, hereafter) for an example. Our equations are simple algebraic balances because the carbonate chemistry of the oceans is essentially in a quasi-steady state on secular timescales $\left(\sim 3 \mathrm{X}\right.$ the residence time of the $\mathrm{HCO}_{3}^{-}$in the oceans). The other two equations are statements of thermody-

b

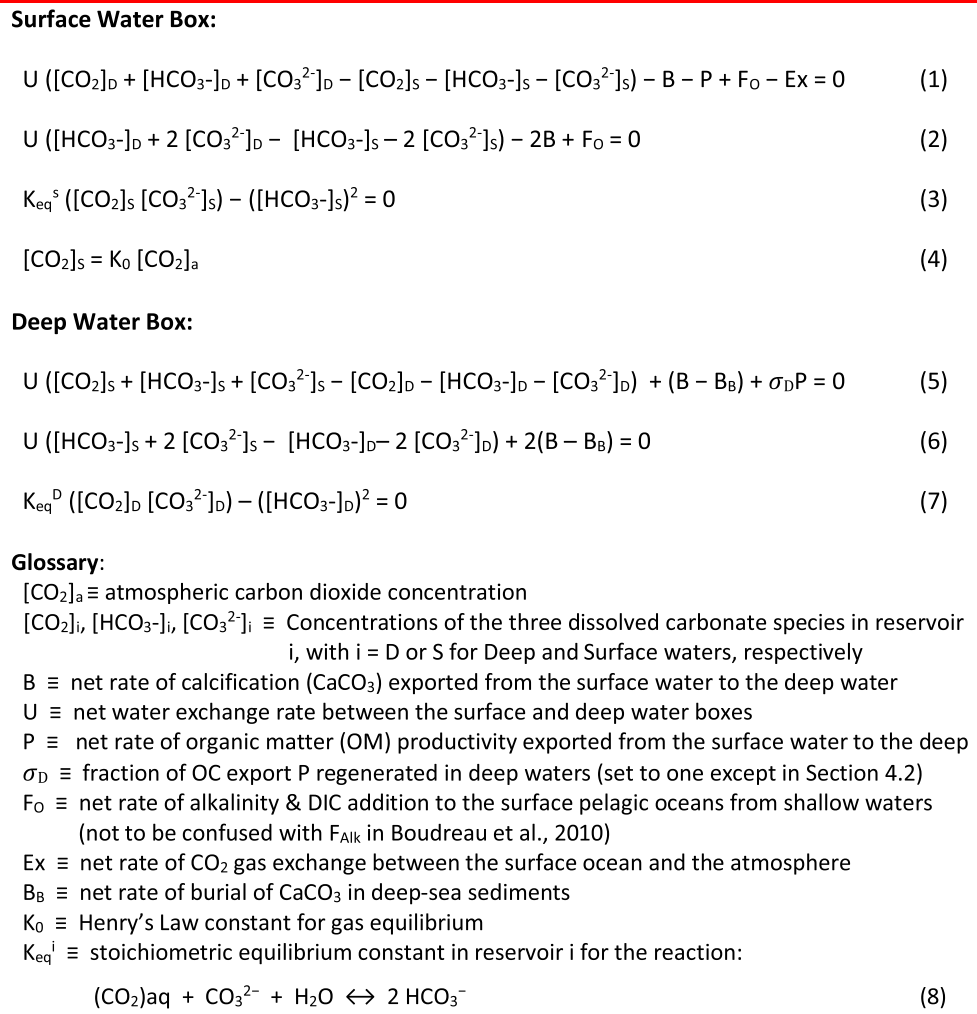

Thus, $\mathrm{K}_{\mathrm{eq}}{ }^{\mathrm{i}}$ is the ratio of the first dissociation constant of carbonic acid $\left(\mathrm{K}_{1}\right)$ to the second dissociation constant $\left(K_{2}\right)$, i.e., $K_{e q}=K_{1} / K_{2}$.

Fig. 1. (continued) 
namic equilibrium between the carbonate species in each reservoir. The other rate terms in these equations are defined in Fig. $1 \mathrm{~b}$.

The assumptions in these equations are: a) a two-box model provides an acceptable representation of oceanic carbonate chemistry on a timescale $\geq 10^{6} \mathrm{yr} ; \mathrm{b}$ ) a simple exchange flow, $U$, is a satisfactory parameterization of secular timescale water exchange; c) no appreciable organic matter is buried in the deep sea, i.e., less than $0.3 \%$ of export flux is buried (Sarmiento and Gruber, 2006); consequently, so that organic carbon export production $P$ in (1) is balanced by a negative $\sigma_{\mathrm{D}} \mathrm{P}$ in (5), where $\sigma_{\mathrm{D}}$ is the fraction of exported carbon that is regenerated in deep waters. Initially we assume $\sigma_{\mathrm{D}}=1$, and we demonstrate the accuracy of this assumption in Section 4.2; and, d) the net alkalinity input to the pelagic ocean, $F_{O}$, is an unknown; $F_{O}$ can also be equated to the net DIC input to the pelagic ocean needed to support the inorganic carbon balance, which is well approximated in the oceans where the bicarbonate concentration is $\sim 20 \mathrm{X}$ the carbonate ion concentration. Moreover, we ignore any dissolution of $\mathrm{CaCO}_{3}$ within sediments driven by oxic organic matter decomposition (Emerson and Bender, 1981) because that process has not been convincingly demonstrated as important in pelagic sediments (e.g., Jahnke et al., 1994; Jahnke and Jahnke, 2004).

The 7 equations in Fig. 1 apparently contain 16 unknowns, i.e., $\left[\mathrm{CO}_{2}\right]_{\mathrm{S}},\left[\mathrm{HCO}_{3}{ }^{-}\right]_{\mathrm{S}},\left[\mathrm{CO}_{3}{ }^{2-}\right]_{\mathrm{S}},\left[\mathrm{CO}_{2}\right]_{\mathrm{D}},\left[\mathrm{HCO}_{3}{ }^{-}\right]_{\mathrm{D}},\left[\mathrm{CO}_{3}{ }^{2-}\right]_{\mathrm{D}}, U, \mathrm{~B}, \mathrm{P}$, $F_{\mathrm{O}}, \mathrm{Ex},\left[\mathrm{CO}_{2}\right]_{\mathrm{a}}, K_{\mathrm{eq}} \mathrm{S}, K_{\mathrm{eq}}{ }^{\mathrm{D}}, K_{\mathrm{O}}$, and $B_{\mathrm{B}}$; thus, there are 9 extra unknowns $\left(\sigma_{D}\right.$ is discussed in Section 4.2). That situation looks bleak and typical of all such models of the past. There are, fortunately, assumptions, simplifications and additional relations that can be used. Simplification starts by adding (2) and (6) to get:

$F_{\mathrm{O}}=2 B_{\mathrm{B}}$

which means that the input of (carbonate) alkalinity and DIC to the pelagic oceans to support the inorganic carbon balance is twice the burial rate of $\mathrm{CaCO}_{3}$. Equation (9) allows us to calculate $F_{O}$ if we know $B_{\mathrm{B}}$ and that will replace equation (6). In addition, combining equations (1), (5) and (9) gives:

$\mathrm{Ex}=B_{\mathrm{B}}$

which says that the rate of $\mathrm{CaCO}_{3}$ burial is equal to the net $\mathrm{CO}_{2}$ flux out of the (pelagic) surface oceans. Note that we assume that volcanic emissions are direct to the atmosphere and thus captured in our $\mathrm{CO}_{2}$ record so that they do not appear in our equations. Consequently, equation (10) can replace equation (5).

Next, we add new information to resolve the unknowns. First, assume that $\left[\mathrm{CO}_{2}\right]_{\mathrm{a}}$ is known from proxies and other measurements (Beerling and Royer, 2011) and can be represented by the smooth curve in Fig. 2a. (The boron-isotope-based $\mathrm{CO}_{2}$ data have been removed from this compilation for reasons explained below.) This approach removes one extra unknown, and because of equation (4), $\left[\mathrm{CO}_{2}\right]_{S}$ is immediately calculable. We fully realize that adopting the $\left[\mathrm{CO}_{2}\right]_{\mathrm{a}}$ curve in Fig. 2a is a significant step, and we test its influence in Fig. S3 of the SI. Furthermore, the $\mathrm{pCO}_{2}$ record is under constant revision, so much so that our results can only be considered provisional - see Fig. S8 of the SI, using the Sosdian et al. (2018) data.

Results from Boudreau and Luo (2017) provide both $\left[\mathrm{CO}_{3}{ }^{2-}\right]_{\mathrm{D}}$ and $B_{\mathrm{B}}$ time series, as functions of the CCD records offered respectively by Lyle et al. (2008) and Pälike et al. (2012); using these former series thereby drops the unknowns to 6 - see Figs. 2b-d. The Lyle et al. (2008) record is a recalibration of the (scientifically ancient) van Andel (1975) record, and the latter's coarseness does limit its utility. The Pälike et al. Pacific CCD record shares some of the data of the Lyle et al. (2008) ocean-wide CCD record, but is chrono-stratigraphically better constrained and temporally better resolved, thus revealing finer detail; nevertheless, the Pälike et al.-record relies upon equatorial cores and some of the observed structure may simply be related to long-term shifts in the ITCZ and the corresponding location of peak surface ocean productivity, rather than overall changes in ocean carbonate chemistry. We can expect some divergence in predictions from these two records, especially in the last 30 Ma of the Cenozoic. Note also that the Boudreau and Luo (2017) burial retrodictions are not in agreement, in either magnitude or trends, with those offered by Hilting et al. (2008), based on carbon-isotope modeling, and that issue cannot be resolved here.

The thermodynamic constants $K_{\mathrm{eq}}^{\mathrm{S}}, K_{\mathrm{eq}}^{\mathrm{D}}$ and $K_{0}$ can be calculated from the equations in Hain et al. (2015) - see Fig. 2e, using ocean and atmospheric temperature records (Hansen et al., 2013; Beerling and Royer, 2011) and the secular changes in dissolved $\mathrm{Ca}^{2+}$ and $\mathrm{Mg}^{2+}$ given in Hain et al. (2015). We considered the effects of the error in $K_{1}$ noted by Zeebe and Tyrrell (2018) in the Hain et al. (2015) formulation and found it to be small (see Fig. S2). We also tested thermodynamic constants derived with temperatures set to $\pm 2{ }^{\circ} \mathrm{C}$ from the Hansen et al. curve, which had no tangible effect on our results. There are now only 3 extra unknowns, $P, B$ and $U$.

Berger and Herguera (1992) have collected data on present-day export fluxes of organic matter and $\mathrm{CaCO}_{3}$. Using their data, we derived the relationship

$P=f B^{m}$

where $f$ and $m$ are fitting constants. Fig. 2f shows that our best fit to this data results from $f=0.04$ and $m=1.43$ when $B$ and $P$ are in units of $\mathrm{Gmola}^{-1}$. We assume that this present-day equation can be applied in the past, and we admit to the uncertainty of that extrapolation. To test that assumption, we also solved our model with a constant of $P=2 \times 10^{5} \mathrm{Gmola}^{-1}$, i.e., the value observed today, $P=4 \mathrm{~B}$, a commonly stated approximation (e.g., Broecker and Peng, 1982); however, the exact $P$ to $B$ relationship is of second-order importance (Fig. S4). The extra unknown count is down to 2 .

Boudreau and Luo (2017) used their model not only to generate a consistent $\mathrm{CaCO}_{3}$ burial record $\left(B_{\mathrm{B}}\right)$, but to calculate the total rain rate of $\mathrm{CaCO}_{3}$ to the sediment-water interface of the pelagic oceans, $\mathrm{B}_{\mathrm{SR}}$. This is relevant because $B$ is related to $B_{\mathrm{SR}}$; specifically,

$B-B_{\mathrm{NS}}=B_{\mathrm{SR}}$

where $B_{\mathrm{NS}}$ is the amount of the export of $\mathrm{CaCO}_{3}$ that dissolves in the water column. Fiadeiro (1980), Milliman (1993), Milliman et al. (1999), Sabine et al. (2002), and Feely et al. (2004) have all argued for the existence of an alkalinity source from water-column dissolution of $\mathrm{CaCO}_{3}$, particularly at depths just below the thermocline, but above the saturation horizon. Many mechanisms have been proposed for this source, including aragonite and Mg-calcite dissolution, forcing by $\mathrm{CO}_{2}$ generated by microbial reactions, and digestion in animal guts. The exact mechanism is not important to our study other than the fact that it seems largely independent of the calcite saturation state of the water mass in which it occurs.

Based on their data, Feely et al. (2004) advance that $B_{\mathrm{NS}}$ is about $50 \%$ of $B$. It is completely unknown if this fraction was at a similar level in the past. Assuming that $B_{\mathrm{NS}}$ is driven by $\mathrm{CO}_{2}$ from the oxidation of associated organic matter, then to a first approximation, the rate of water column dissolution scales with $B$ :

$B_{\mathrm{NS}}=\varepsilon B$

where $\varepsilon$ is the fraction dissolved in the water column. We use $\varepsilon$ equal to 0.5 (Feely et al., 2004); this is likely to be a maximum value as the saturation horizon for calcite was shallower in 

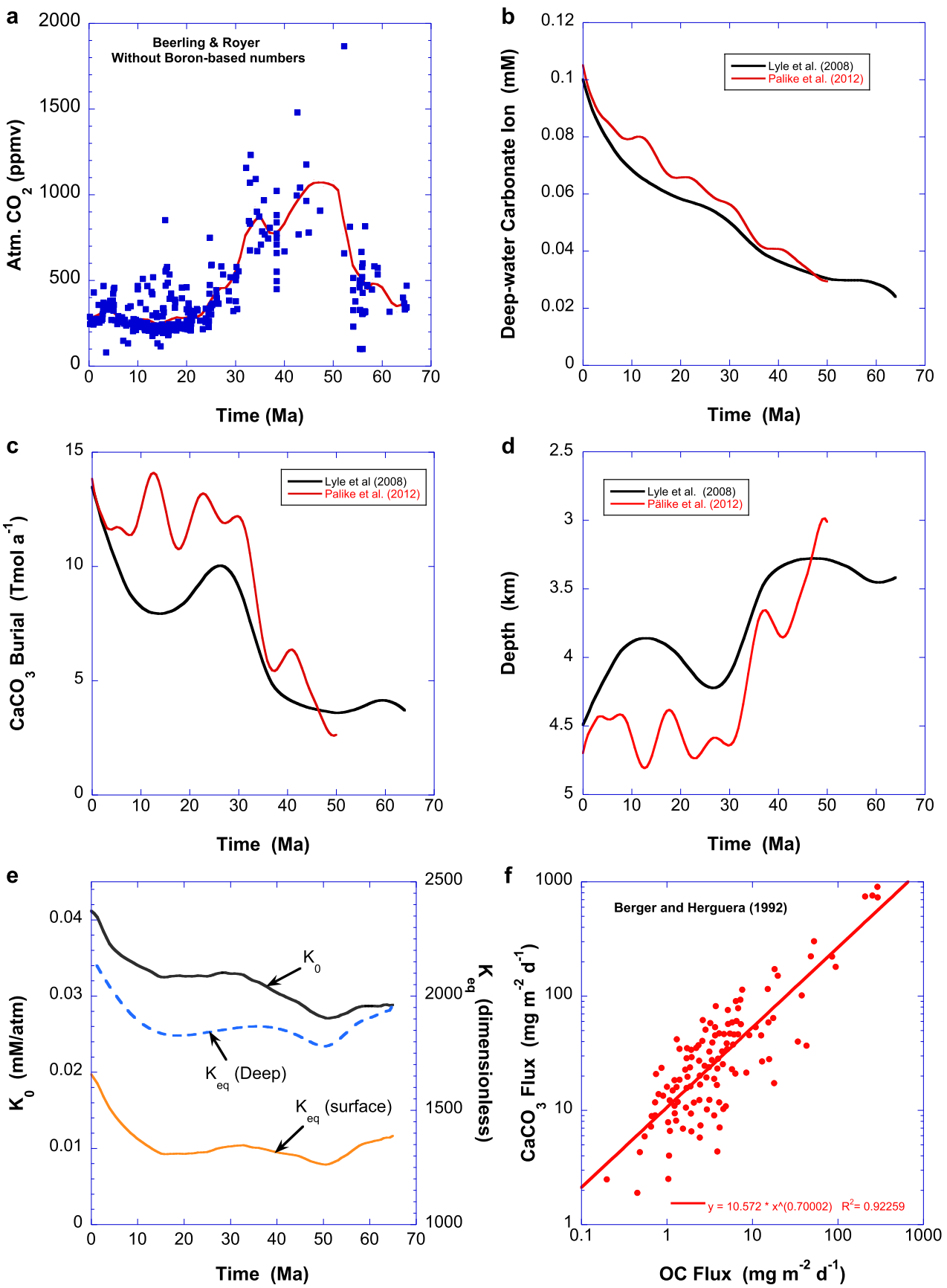

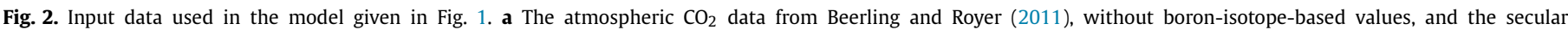

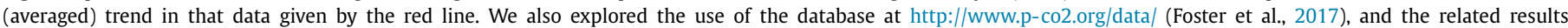

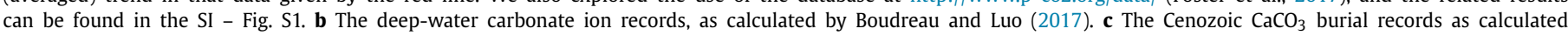

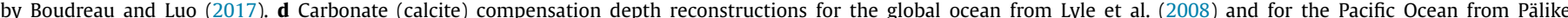

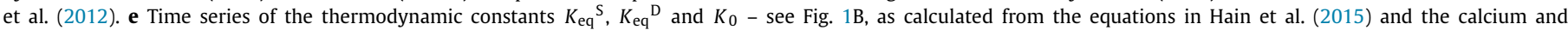

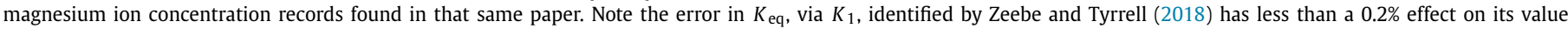
- see Fig. S2. f Linear regression of the Berger and Herguera (1992) data relating the $\mathrm{CaCO}_{3}$ flux to the deep ocean to the organic carbon (OC) flux.

the past, which would shrink the depth range wherein $B_{N S}$ could be generated. The effects of changing $\varepsilon$ are illustrated in Fig. S5 (parts 1 and 2) of the SI. These are not large for dissolved species and $\mathrm{pH}$, but the retrodicted $\mathrm{P}$ exhibits some sensitivity to the value of $\varepsilon$. Finally, using equation (12) and (13):

$B=B_{\mathrm{SR}}(1-\varepsilon)^{-1}$

and as a result, another extra unknown is eliminated.

This only leaves the water exchange rate between the surface and deep oceans, $U$. Sadly, the variation of $U$ over the Cenozoic is unknown. Except in sub-oceans for sub-secular timescales, there is no strong evidence from GCM models that the overall overturning rate of the oceans was very different in the past (Bice and Marotzke, 2001; Heinze and Ilyina, 2015). The present-day value is between 30 and 50 Sv (Sarmiento and Toggweiler, 1984; Broecker et al., 1999). Propitiously, our results do not depend overly on the exact value of $U$ - see Fig. S6. That fortunate result allows us to set $U=50 \mathrm{~Sv}$, with a reasonable degree of confidence that the carbonate chemistry results are robust relative to this parameter. The model is now completely specified. 

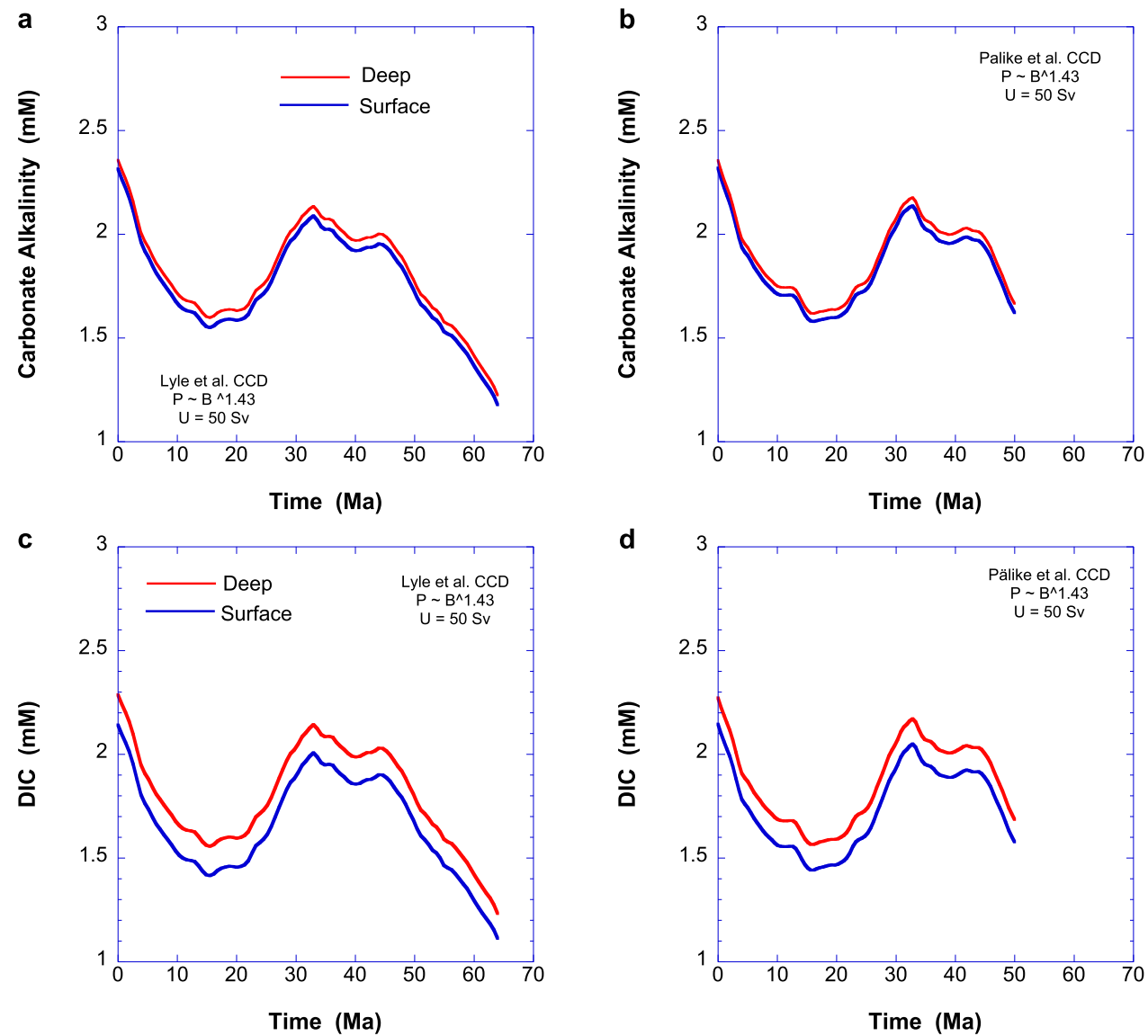

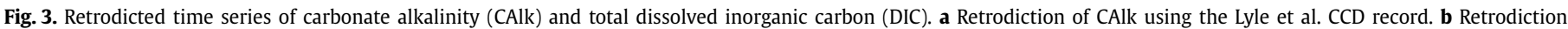
of CAlk using the Pälike et al. CCD record. c Retrodiction of DIC using the Lyle et al. CCD record. d Retrodiction of DIC using the Pälike et al. CCD record.

\subsection{Model solution}

There are now 9 equations, i.e., equations (1)-(4), (7), (9)-(10), (11) and (14), that can be employed to calculate 9 unknowns, i.e., $\left[\mathrm{CO}_{2}\right]_{\mathrm{S}},\left[\mathrm{HCO}_{3}{ }^{-}\right]_{\mathrm{S}},\left[\mathrm{CO}_{3}{ }^{2-}\right]_{\mathrm{S}},\left[\mathrm{CO}_{2}\right]_{\mathrm{D}},\left[\mathrm{HCO}_{3}{ }^{-}\right]_{\mathrm{D}}, \mathrm{B}, \mathrm{P}, \mathrm{F}_{\mathrm{O}}$, and $\mathrm{Ex}$, because $U$ is a fixed known value, $\left[\mathrm{CO}_{2}\right]_{\mathrm{a}}$ is taken from Beerling and Royer (2011) and Foster et al. (2017), B $\mathrm{B}$ and $\left[\mathrm{CO}_{3}{ }^{2-}\right]_{\mathrm{D}}$ are taken from Boudreau and Luo (2017), and the thermodynamic constants are calculated according to Hain et al. (2015). The solution of these equations can be obtained by a simple bisection-anditeration method. The FORTRAN code that implements that method is also part of the Supplemental Information.

\section{Results}

Fig. 3 displays the retrodicted records of CAlk and DIC based on the CCD records from both Lyle et al. (2008) and Pälike et al. (2012) - see Fig. 2e.

Fig. 4 illustrates the retrodicted $\mathrm{pH}$ (total hydrogen ion scale) records; this figure also contains estimated surface $\mathrm{pH}$ values from the boron-proxy (Pearson and Palmer, 2000; Foster et al., 2017), despite any continuing debate on the accuracy of that approach (e.g., Nir et al., 2015).

Fig. 5 displays the retrodicted export productivity $P$ and the export calcification rate, $B$, as well as their ratio, $P / B$. $B$ is perhaps surprisingly constant, regardless of the chosen $C C D$ record, while both $P$ and the $P / B$ ratio exhibit weak dependencies on time over the Cenozoic. Unlike our $B_{\mathrm{B}}$ retrodiction, our modeled $P$ is similar to that predicted by Hilting et al. (2008).

As discussed in the Introduction, other authors have adopted a variety of assumptions to resolve the indeterminacy of their retro- diction models, including constant surface alkalinity or calcite saturation with time and a constant ratio of surface to deep water $\mathrm{CO}_{3}{ }^{2-}$ concentrations. To examine whether these assumptions are likely to be model independent, we present in Fig. 6a\&b the retrodicted carbonate ion ratio and in Fig. $6 c \& d$ the retrodicted surface saturation. In addition, the assumption of constancy of surface alkalinity can be addressed with the results shown in Fig. 3.

\section{Discussion}

\subsection{CAlk and DIC trends}

As a first step, we need to explain the overall trends in the retrodicted time series of CAlk, DIC and pH in Figs. 3 and 4 in relation to the deep-water dissolved carbonate ion concentration, $\left[\mathrm{CO}_{3}{ }^{2-}\right]_{\mathrm{D}}$ (Fig. 2b), the $\mathrm{CaCO}_{3}$ burial rate, $B_{\mathrm{B}}$ (Fig. 2c), the CCD positions, $z_{\mathrm{cc}}$ (Fig. 2d), the atmospheric $\mathrm{CO}_{2}$ record (Fig. 2a), and the calcification rate, $B$ (Fig. 5). Differences in predicted carbonate chemistry between results obtained using the Lyle et al. CCD record and the Pälike et al. CCD record, as illustrated in these figures, appear to be almost trivial, but there is a marked disparity in implied cause. We begin by focusing on the Lyle et al.-based results, as this constitutes a simpler CCD record. Again, we note our model is restricted to the pelagic realm and cannot offer any specifics about the removal of alkalinity on shelves or in shallow seas. (Further, we display borate-corrected total alkalinity in Fig. S7 to illustrate the ease of conversion of our results to TAlk.)

\subsubsection{Results based on the Lyle et al.-CCD record}

The Lyle et al. CCD record shows an overall deepening with Cenozoic progression (Fig. 2d), which results from an increase in 

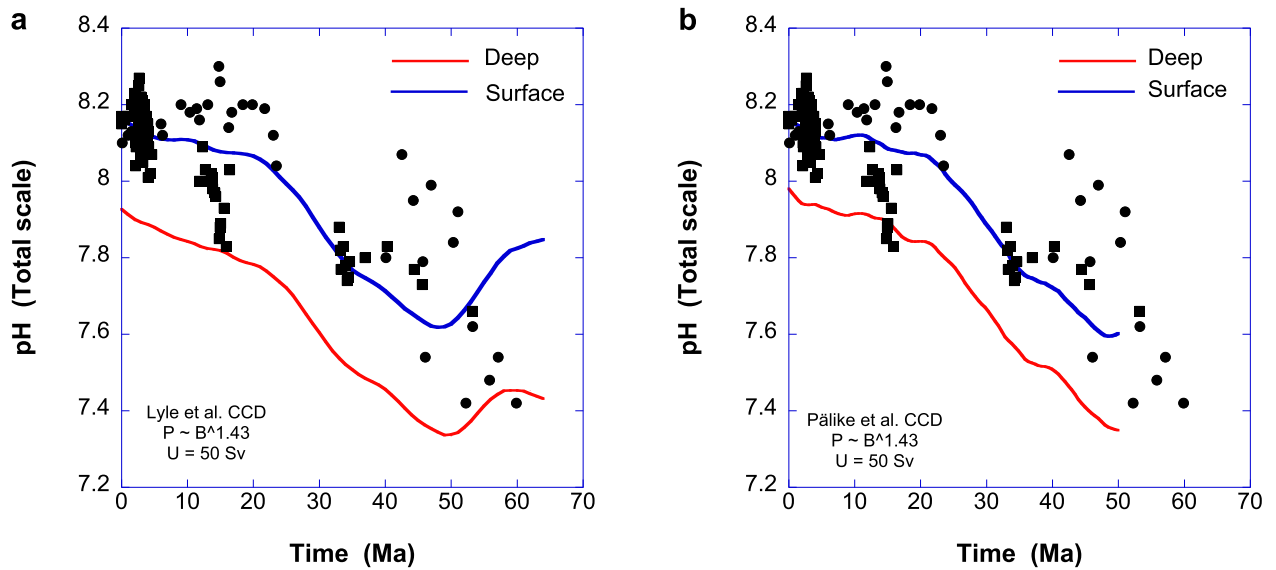

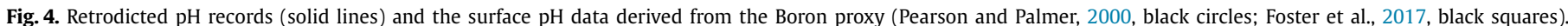

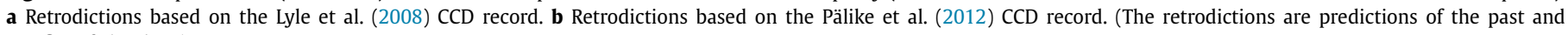
not fits of the data.)
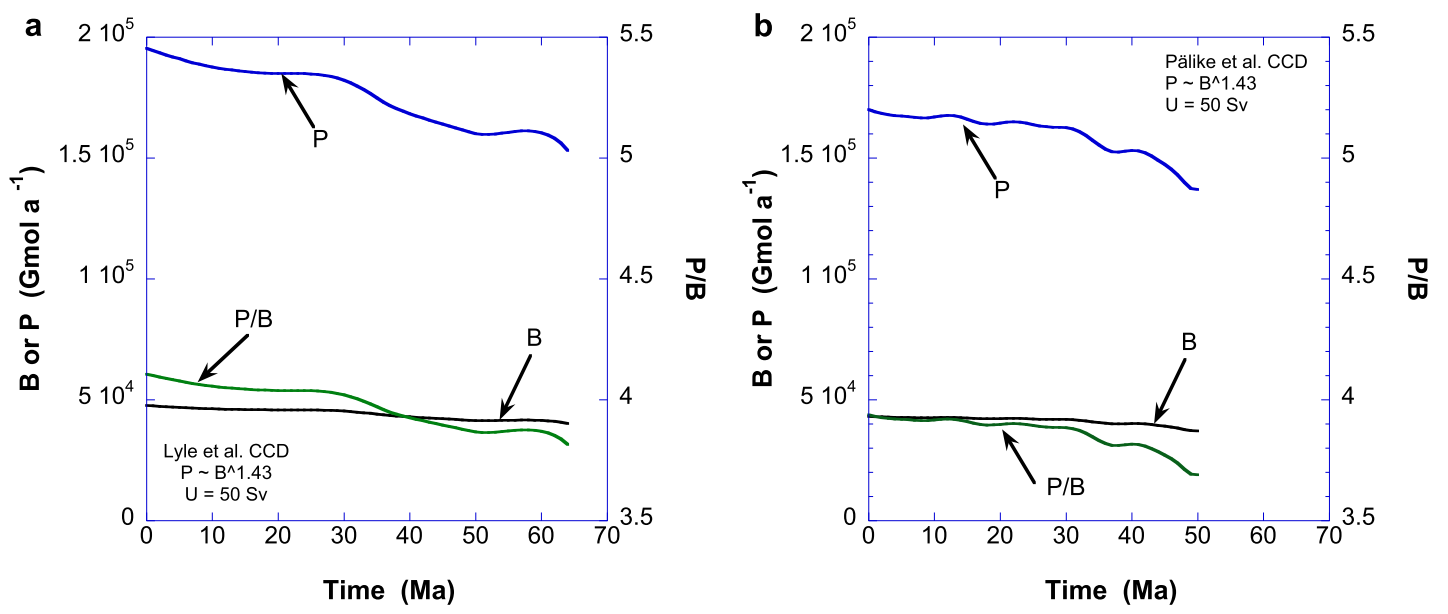

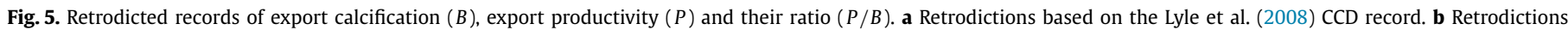
based on the Pälike et al. (2012) CCD record.

either the input of alkalinity $\left(F_{0}\right)$ to the pelagic realm or in the pelagic calcification rate $(B)$. Our results show that $B$ remained essentially constant during the Cenozoic (Fig. 5). This immediately demands a long-term increase in $F_{0}$ as the driver of the mean burial change (Fig. 2c), as required by Equation (9). A deepening CCD and increased burial should coincide with increased bottom water carbonate ion concentration (Fig. 2b), which was shown to be the case by Boudreau and Luo (2017), as also consistent with Tyrrell and Zeebe (2004).

The Lyle et al.-based burial rate (Fig. 2d) exhibits a weak broad maximum between 56 and $40 \mathrm{Ma}$ (Eocene), centered at $\sim 48 \mathrm{Ma}$, which parallels an equally weak maximum in atmospheric $\mathrm{CO}_{2}$ between those times. Note that when Boudreau and Luo (2017) employ the Slotnick et al. (2015) CCD curve, they also retrodict a weak burial maximum (their Fig. 4), centered at $\sim 52 \mathrm{Ma}$. This weak peak in burial requires a similar trend in alkalinity input $\left(F_{0}\right)$ to the pelagic ocean from the nearshore, i.e., Equation (9), but the cause cannot be addressed with our model. The plateau in $\mathrm{CO}_{2}$ between 58-52 Ma then corresponds to a weak decrease in $\mathrm{CaCO}_{3}$ burial (Fig. 2c), despite the fact that this period also contains episodes of strong and rapid $\mathrm{CaCO}_{3}$ dissolution and preservation, e.g., the PETM at $\sim 56$ Ma.

The subsequent increased $\mathrm{CaCO}_{3}$ burial and $\left[\mathrm{CO}_{3}{ }^{2-}\right]_{\mathrm{D}}$ between $\sim 50$ and $\sim 30 \mathrm{Ma}$, i.e., near the onset of Antarctic glaciation, correlate with elevated, but mainly decreasing, atmospheric $\mathrm{CO}_{2}$. The increasing burial (Fig. 2c), in turn, demands increased delivery of alkalinity $\left(F_{0}\right)$ to the pelagic oceans.

Between $\sim 30$ and $\sim 15$ Ma (i.e., the Middle Miocene Climate Transition - MMCT), $\mathrm{CaCO}_{3}$ burial falls, but stays well above the pre-48 Ma levels, which indicates a modest fall in the alkalinity input $\left(F_{O}\right)$. This decrease in accumulation accompanies a reduction in atmospheric $\mathrm{CO}_{2}$ to levels below those at the beginning of the Cenozoic, while the accumulation of carbonate ion in deep water decelerates (Fig. 3a). After $\sim 15 \mathrm{Ma}$, carbonate burial again increases, even though atmospheric $\mathrm{CO}_{2}$ remains low, which requires a net increase in the alkalinity input, i.e., increased weathering, or decreased alkalinity interception, or both.

Unlike the retrodicted deep-water carbonate ion concentration (Boudreau and Luo, 2017), which increases with time (Fig. 2b), both CAlk and DIC display about $\pm 25 \%$ fluctuations (Fig. 3), such that these concentrations are currently at their highest levels. Between 65-32 Ma, the increased CAlk and DIC (Fig. 3) broadly correlate with the rise in atmospheric $\mathrm{CO}_{2}$ (Fig. 2a). In fact, there are local CAlk and DIC maxima at $\sim 48 \mathrm{Ma}$ (the beginning of the Eocene cooling trend) and $\sim 32 \mathrm{Ma}$ (near the start of the Oligocene and the glaciation of Antarctica and possibly the opening of the Drake Passage) that correspond with similar $\mathrm{CO}_{2}$ peaks. Enhanced alkalinity input $\left(F_{O}\right)$ to the pelagic ocean is one logical explanation, which again could be due to increased chemical weathering or lowered alkalinity interception, or both; however, increased atmospheric $\mathrm{CO}_{2}$ in itself could cause such changes. 

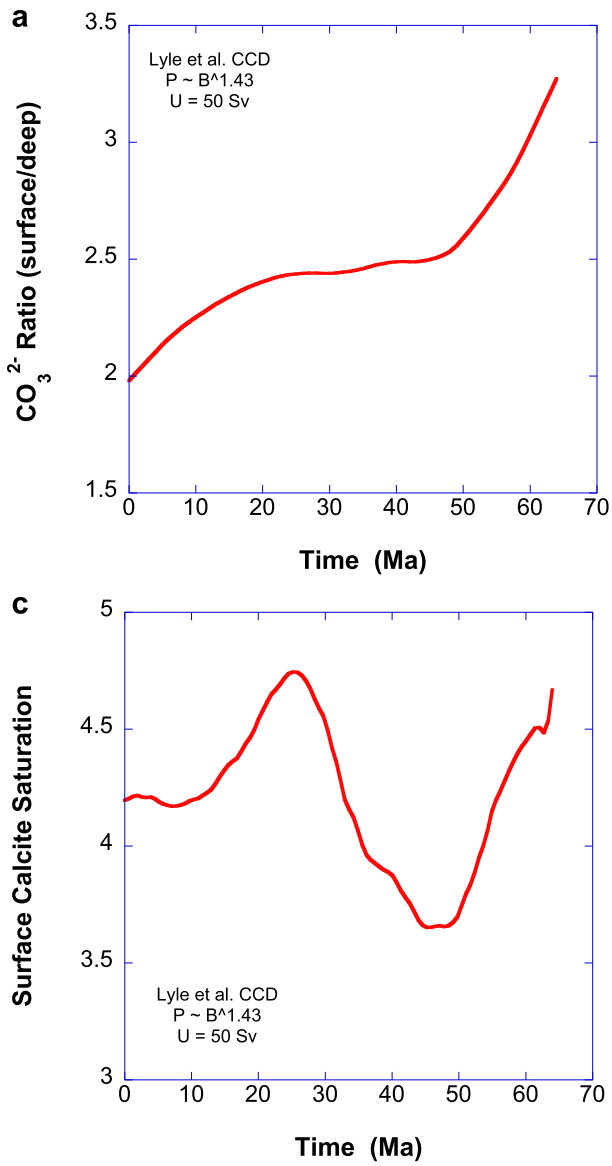
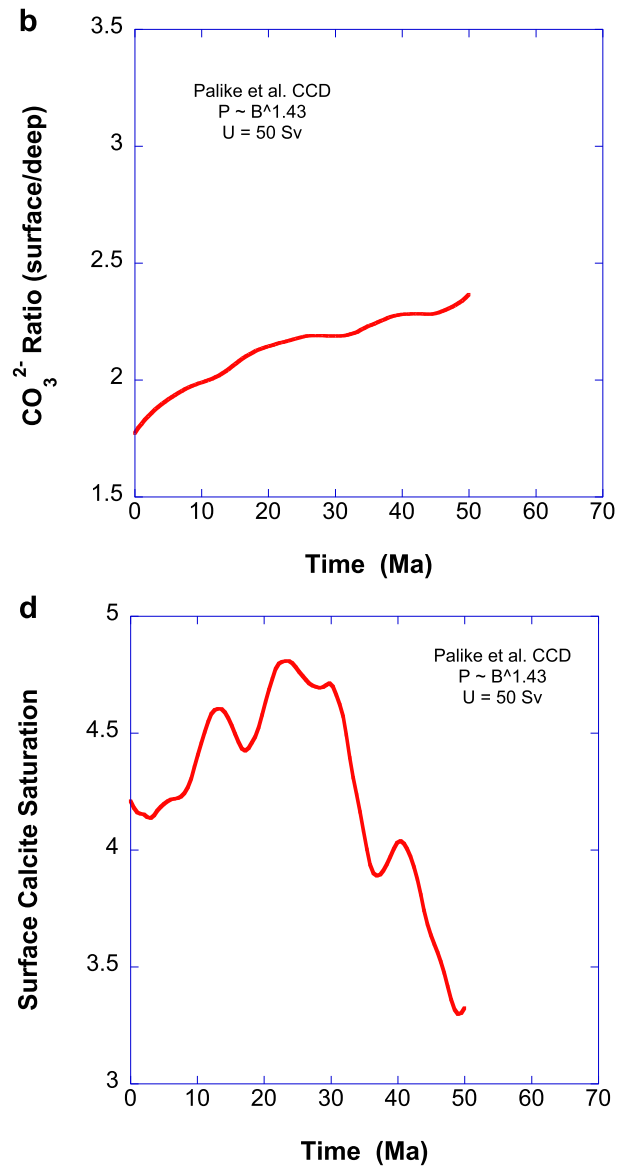

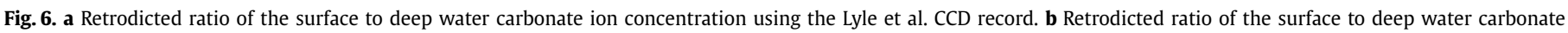

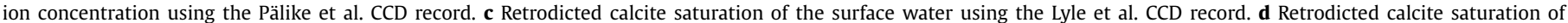
the surface water using the Pälike et al. CCD record.

Between $\sim 32$ Ma and $\sim 15 \mathrm{Ma}$, the Lyle et al.-based results demand that $F_{\mathrm{O}}$ must have dropped because we observe decreasing burial and concentrations of CAlk and DIC. Finally, burial rises strongly after $15 \mathrm{Ma}$, as a result of increased $F_{\mathrm{O}}$, which in turn leads to an increase in both CAlk and DIC (Fig. 3). All of this conforms to a widely held view of the evolution of the carbonate chemistry of the oceans during the Cenozoic, e.g., as reconstructed by Raymo and Ruddiman (1992) or Tyrrell and Zeebe (2004). However, our reconstructed fluctuations in CAlk are considerably smaller than those advanced by Pearson and Palmer (2000), but similar to those in Caves et al. (2016).

\subsubsection{Based on the Pälike et al.-CCD record}

The Pälike et al.-based model contains a surprise. Retrodicted CAlk and DIC records trend similarly to the Lyle et al.-based model (Fig. 3), if shifted downward slightly; yet, the Pälike et al.-based model retrodicts a dissimilar burial record (Fig. 2c) and, consequently evolution of $F_{0}$. Earlier in the Cenozoic (50 to $\sim 32 \mathrm{Ma}$ ), the burial generally increases, meaning that $F_{0}$ does so too, and CAlk and DIC rise. However, after $\sim 32 \mathrm{Ma}$, the CAlk and DIC fall, while the burial is, to a reasonable approximation, constant with smaller variations about that mean $\left(\sim 12.5 \mathrm{Tmola}^{-1}\right)$. There is no substantial fall in $F_{0}$ between $\sim 32 \mathrm{Ma}$ and $\sim 15 \mathrm{Ma}$ to drive the decreases in CAlk and DIC.

The clear correlation with the fall in CAlk and DIC is the drop in atmospheric $\mathrm{CO}_{2}$. When $\left[\mathrm{CO}_{2}\right]_{\mathrm{a}}$ falls, $\left[\mathrm{CO}_{2}\right]_{S}$ changes proportionately. During the $\sim 32 \mathrm{Ma}$ and $\sim 15 \mathrm{Ma}$ period, $\left[\mathrm{CO}_{2}\right]_{S}$ drops far more than $\left[\mathrm{CO}_{3}{ }^{2-}\right]_{\mathrm{s}}$ rises (Fig. 6), i.e., 62\% drop versus a 30\% rise. Accordingly, the bicarbonate ion must decrease to maintain Equa- tion (3), and a reduction in bicarbonate ion lessens both CAlk and DIC, as seen in Fig. 3 .

Between $\sim 15$ Ma and today, the CAlk and DIC rose considerably (Fig. 3), whereas there was no systematic rise in burial (Fig. 2c) and thus $\mathrm{F}_{\mathrm{O}}$. Atmospheric $\mathrm{CO}_{2}$ remained essentially flat. This draws our attention to the $K_{\text {eq }}$ records (Fig. 2d), which climb in both deep and surface oceans with decreasing ocean temperature over the last $15 \mathrm{Ma}$. These increases in $K_{\text {eq }}$ account precisely for the increases in CAlk and DIC. This role of thermodynamics in the carbonate system of the world's oceans during the past $15 \mathrm{Ma}$ is a novel finding, and contrasts with the weathering-alkalinity input control suggested by the Lyle et al.-based model. Note that a thermodynamically controlled situation would not rule out increased weathering over the last $\sim 15 \mathrm{Ma}$, only that the resulting alkalinity does not reach the pelagic ocean due to nearshore removal. (Note that the Lyle et al.-based CAlk and DIC also have this effect, but in that case, it is small compared to the alkalinity forcing.)

\subsubsection{Based on a revised Pälike et al.-CCD record}

The Lyle et al.-based and Pälike et al.-based retrodictions of CAlk, DIC and pH (Figs. 3 and 4) are not identical, but the differences are second order on secular timescales, even though the implied mechanisms causing these trends during the last $15 \mathrm{Ma}$ are decidedly different. The Pälike et al. (2012) record effectively begins at $50 \mathrm{Ma}$, and we were curious if this record was extended to $55 \mathrm{Ma}$, whether this similarity continued. Therefore, the pre-44 Ma data found in Fig. 2 in Pälike et al. (2012) can be interpreted somewhat differently and combined with that in Leon-Rodriguez and Dickens (2010) to create an alternative CCD record for the period 

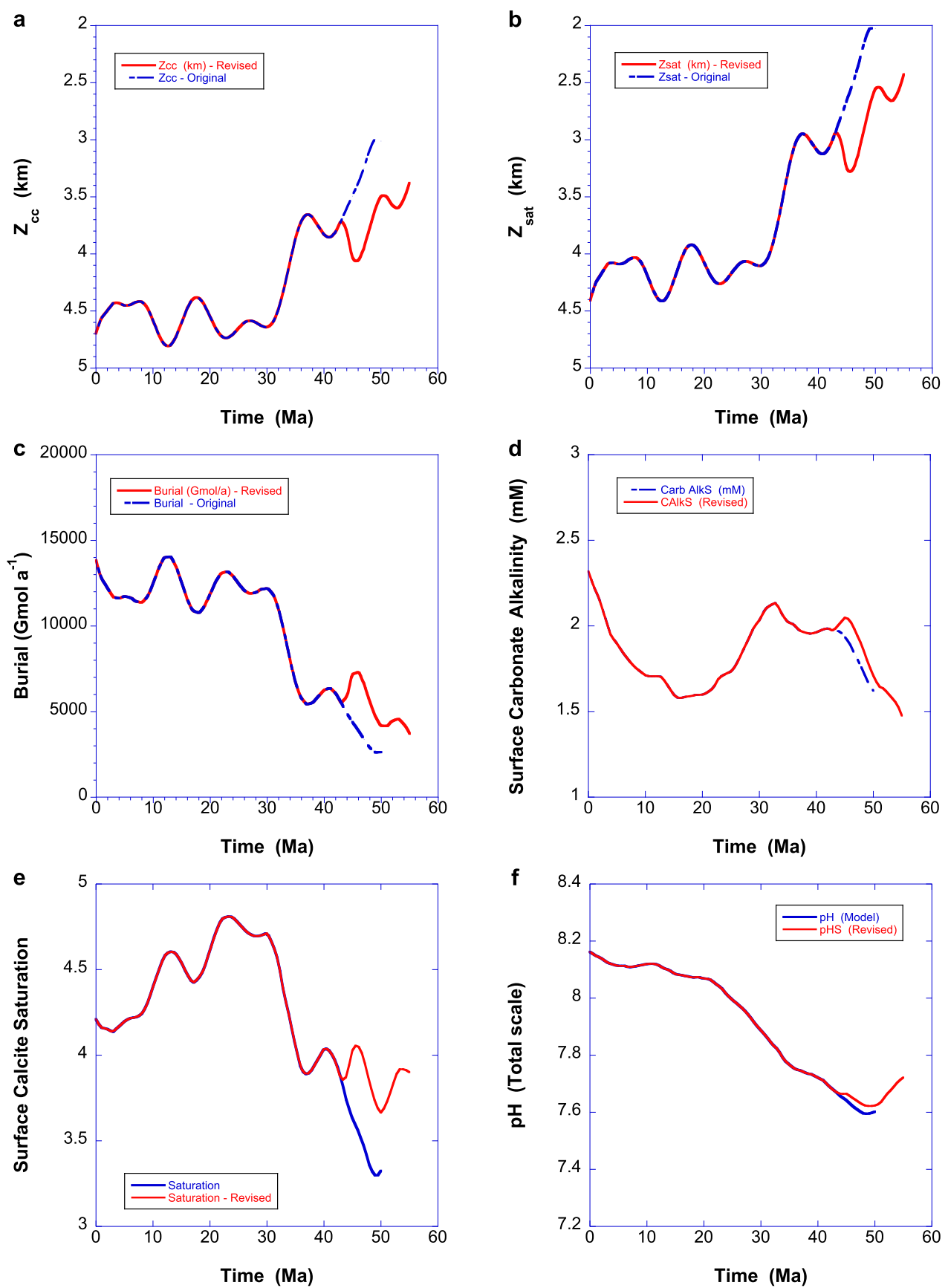

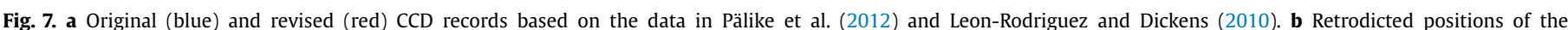

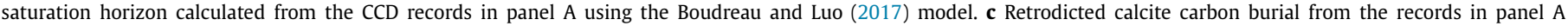

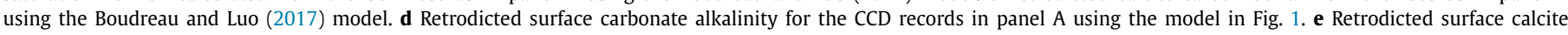
saturation for the CCD records in panel A using the model in Fig. 1. f Retrodicted surface pH for the CCD records in panel A using the model in Fig. 1.

44-55 Ma; this is illustrated in our Fig. 7a. The revised $z_{\mathrm{cc}}$ record is then deeper by between 0.4 and $0.9 \mathrm{~km}$.

From this revised $z_{\mathrm{cc}}$ record, we are able to calculate corresponding revised $\mathrm{z}_{\text {sat }}$ (saturation horizon depths - Fig. 7b) and a revised calcite-carbon burial record (Fig. 7c) using the model in Boudreau and Luo (2017). $z_{\text {sat }}$ is distinctly lower and, consequently, more calcite is preserved. However, the latter comes at a time of highly diminished $\mathrm{CaCO}_{3}$ preservation in the deep oceans, so that this increase in preservation is small in absolute terms.

Fig. $7 d$ illustrates the retrodicted carbonate alkalinity of the surface waters and a small peak now appears at around $48 \mathrm{Ma}$ and the revised values are higher, but the difference with the original Pälike et al.-based curve is very small, i.e., $\sim 2.5 \%$. Fig. 7e displays the calcite saturation state of the surface, and the difference with the original retrodiction is about 0.5 out of a background of about 3.8, which is modest. Finally, Fig. $7 \mathrm{f}$ shows that the retrodicted $\mathrm{pH}$ of the surface waters is trivially dissimilar to the original Pälike et al.-based retrodiction. All this confirms that our dissolved carbonate chemistry results are not greatly sensitive to the details of the input CCD records.

\subsection{Effects of organic carbon burial}

The assumption of no pelagic organic carbon (OC) burial may seem controversial, but it is easily shown that even a strongly exaggerated pelagic OC burial does not affect our findings in any 

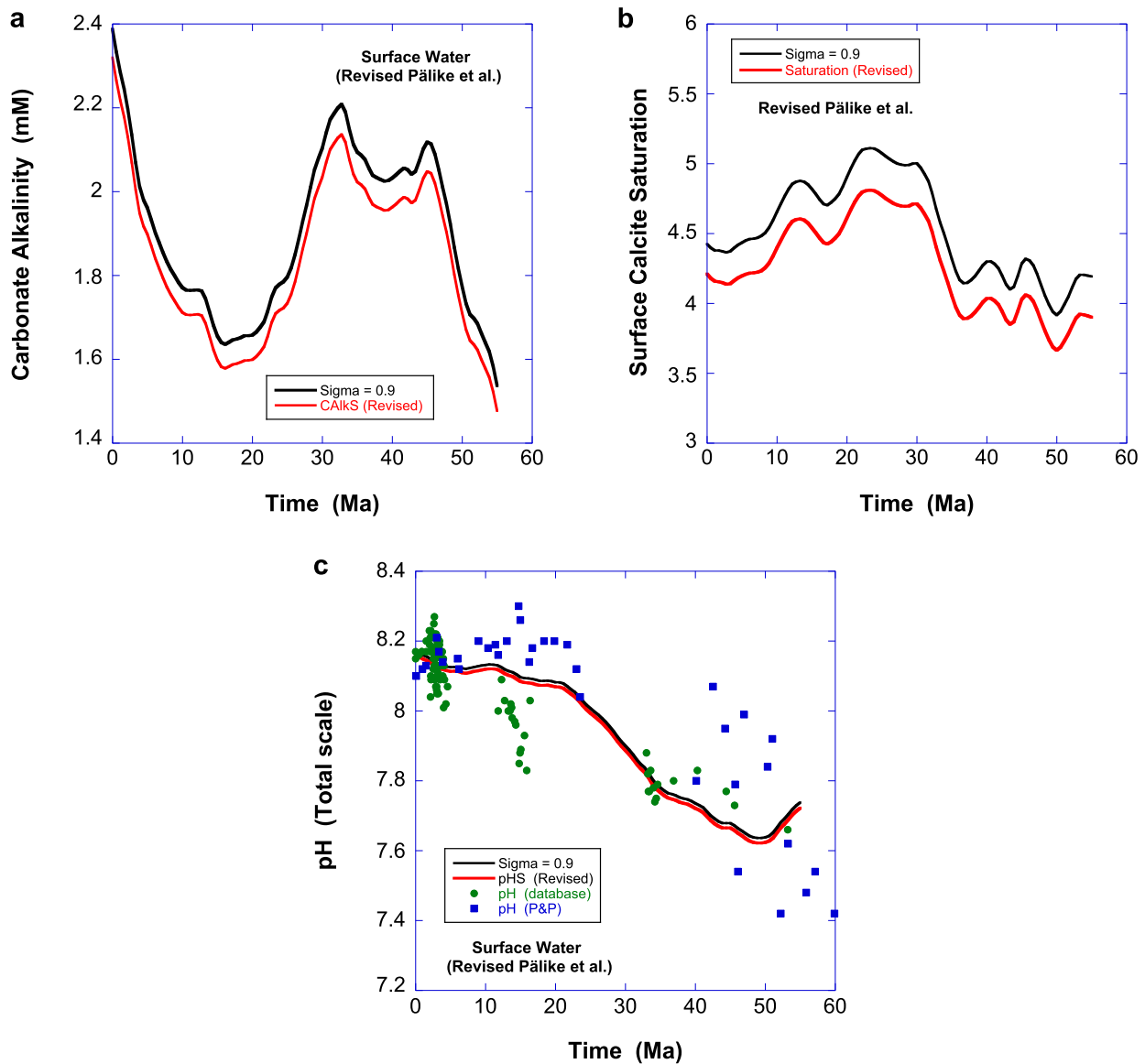

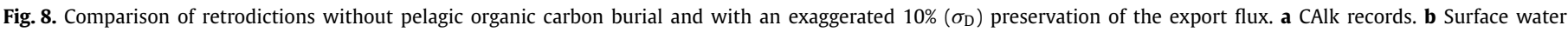

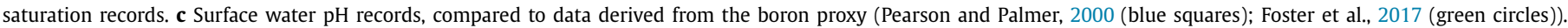
Retrodictions are based on the revised Pälike et al. CCD, as in Fig. 7. See text for further discussion.

significant way. We re-ran our model with a fixed (non-zero) fraction of organic carbon burial $\left(\sigma_{\mathrm{D}}\right)$. As noted earlier, today's pelagic oceans export (our $P$ ) $\sim 550 \mathrm{TmolCa}^{-1}$ at $100 \mathrm{~m}$ (Sarmiento and Gruber, 2006, pp. 260-266), but ultimately bury in pelagic sediments only $1.6 \mathrm{TmolCa}^{-1}$; thus, the leak through burial is only $0.3 \%$ of export. These numbers explain why we previously set regeneration equal to export in our model. Meanwhile our model predicts an export of $170 \mathrm{Tmola}^{-1}$, but that is between at $\sim 200 \mathrm{~m}$, and burial would account for a loss of $\sim 1 \%$. So, we generously assume that $10 \%$ of the OC export is buried. Fig. 8 displays re-calculations of the retrodictions of surface $\mathrm{pH}$, CAlk and saturation with a $10 \%$ leak $\left(\sigma_{\mathrm{D}}=0.9\right)$.

Clearly, these figures demonstrate that a leak of this (large) magnitude does not produce a measurable difference in retrodicted $\mathrm{pH}$ (about $1 \%$ ) and only a modest difference in surface CAlk $(<6 \%)$ and saturation $(<3 \%)$; deep water response is entirely similar. Yet, this model leak is massively greater than the known present-day escape from benthic regeneration, i.e., $10 \%$ versus $1 \%$; if we had used $0.3 \%$ escape, there would be no quantitative differences at all. These results highlight that our treatment of OC burial is entirely justified.

\section{3. $\mathrm{pH}$ records}

Fig. 4 illustrates the retrodicted $\mathrm{pH}$ time series with both the Lyle et al.-based model and the Pälike et al.-based model. Also displayed are paleo-pH estimates from Boron-proxy measurements (compiled at http://www.p-co2.org/data/). These model pH records are predictions, not fits, and the concurrence between Boronisotope data and models is an encouraging sign of the validity of our results. Moreover, our predictions are consistent with those of Tyrrell and Zeebe (2004) for the last $50 \mathrm{Ma}$, but they deviate for earlier times based on the Lyle et al-CCD record.

Surface water $\mathrm{pH}$ reached a minimum at the height of atmospheric $\mathrm{CO}_{2}$ around $48 \mathrm{Ma}$. Between $\sim 48$ and $\sim 15 \mathrm{Ma}$, pH rose as atmospheric $\mathrm{CO}_{2}$ stabilized and then dropped. Thereafter, $\left[\mathrm{CO}_{2}\right]_{\mathrm{a}}$ is roughly constant and so is the surface $\mathrm{pH}$. The deep-water $\mathrm{pH}$ simply mirrors the deep-water value, offset by a small value as a result of higher DIC.

\subsection{Past assumptions}

As stated in the Introduction, past attempts to retrodict the ocean's carbonate chemistry have invoked three common assumptions: (1) constant surface alkalinity, (2) constant surface saturation, and (3) constant $\left[\mathrm{CO}_{3}{ }^{2-}\right]_{S}$ to $\left[\mathrm{CO}_{3}{ }^{2-}\right]_{\mathrm{D}}$ ratio. If they are model-independent results, then they should emerge from our own calculations.

Fig. 3 shows that we retrodict a $67 \%$ change in CAlk of surface waters over the Cenozoic, as opposed to the constancy or salinity dependence adopted by Hönisch and Hemming (2005). That is not a trivial variation, and it has implications for calculating $\left[\mathrm{CO}_{2}\right]_{\mathrm{a}}$ from pH proxy data (e.g., Pearson and Palmer, 2000; Hönisch and Hemming, 2005; Foster, 2008). Fig. 6 Panels C\&D display the calcite surface saturation retrodiction and that quantity changes by $\sim 30 \%$ over the Cenozoic; the deviation from constancy seems modest; however, this $30 \%$ variation corresponds with a $3 \mathrm{X}$ change in retrodicted $\left[\mathrm{CO}_{2}\right]_{s}$. The difference in a retrodicted $\left[\mathrm{CO}_{2}\right]_{a}$ using our varying $\left[\mathrm{CO}_{3}{ }^{2-}\right]_{\mathrm{S}}$ and a $\left[\mathrm{CO}_{2}\right]_{\mathrm{a}}$ from an assumed constant saturation could be great indeed. Finally, Fig. $6 a \& b$ display the 

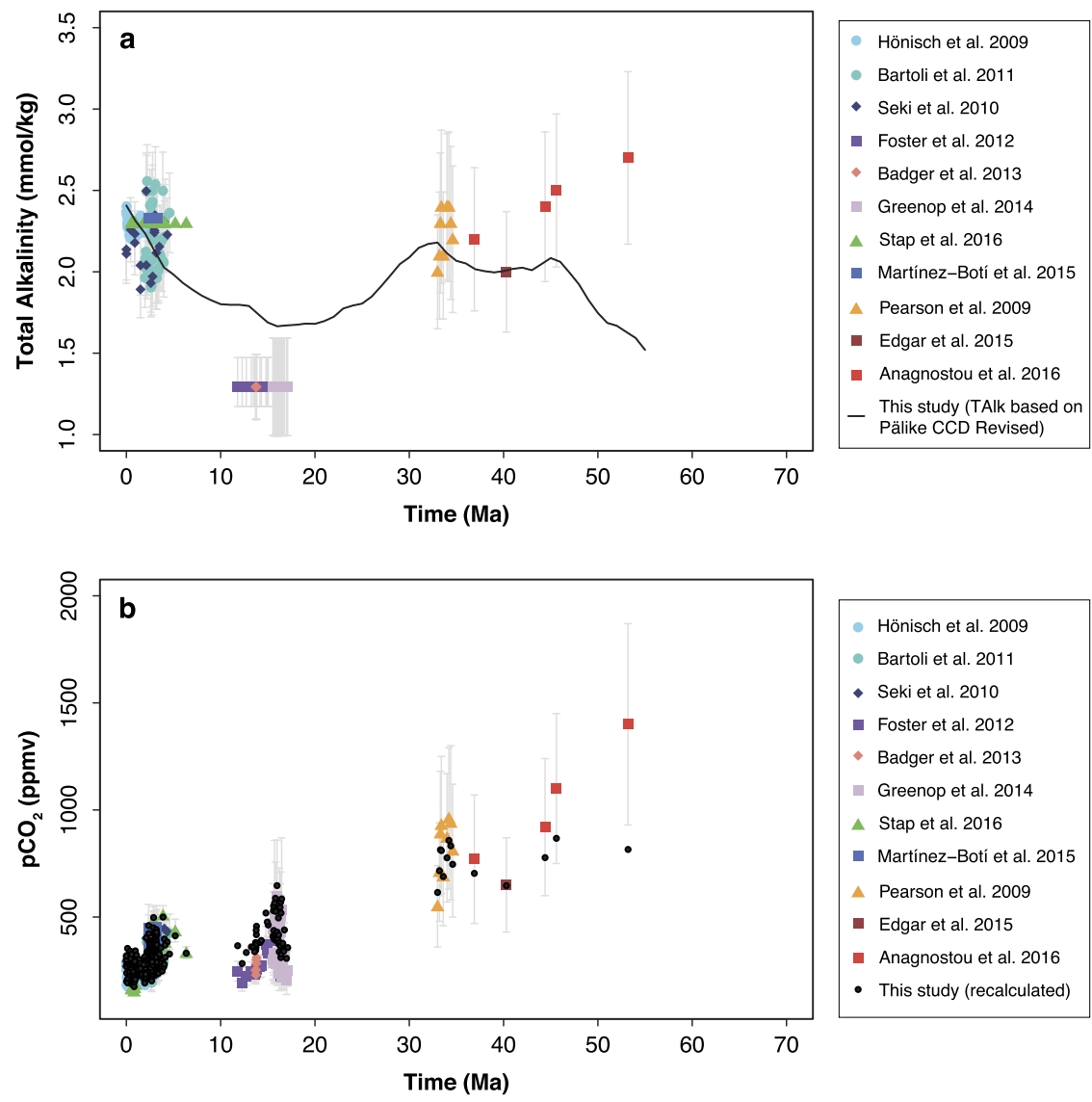

\begin{tabular}{|l|} 
- Hönisch et al. 2009 \\
- Bartoli et al. 2011 \\
- Seki et al. 2010 \\
- Foster et al. 2012 \\
- Badger et al. 2013 \\
- Greenop et al. 2014 \\
- Stap et al. 2016 \\
- Martínez-Botí et al. 2015 \\
- Pearson et al. 2009 \\
- Edgar et al. 2015 \\
- Anagnostou et al. 2016 \\
- This study (recalculated) \\
\hline
\end{tabular}

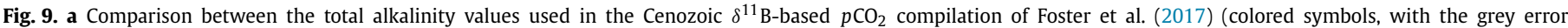

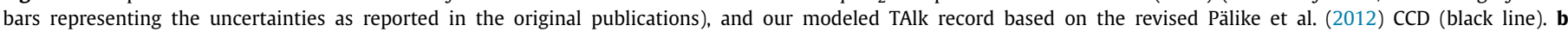

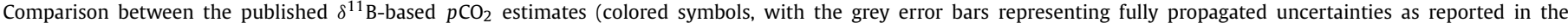

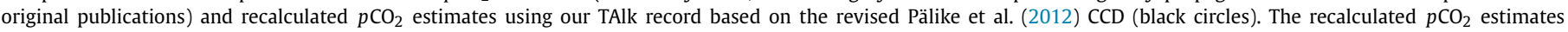
have the same total uncertainties as the original estimates, but for clarity these are not displayed again.

$\left[\mathrm{CO}_{3}{ }^{2-}\right]_{\mathrm{S}} /\left[\mathrm{CO}_{3}{ }^{2-}\right]_{\mathrm{D}}$ ratio with time. This quantity changes by $\sim 30 \%$ in the Pälike et al.-based model and 63\% in the Lyle et al.-based model. Such deviations from constancy could result in significant uncertainties, particular in any prediction of $\left[\mathrm{CO}_{2}\right]_{\mathrm{a}}$ from $\left[\mathrm{CO}_{3}{ }^{2-}\right]_{\mathrm{D}}$. It remains to be seen which set of assumptions, i.e., ours versus those in past studies, better approximates the oceans.

One interesting result from our model is that both $B$ and $P$ (calcification and productivity rates) vary relatively weakly over the Cenozoic, which suggests that an assumption of constant $B$ or $P$ or $B / P$ should generate results compatible with our own.

\subsection{Implications for boron-based $\mathrm{pCO}_{2}$ reconstructions}

Boron isotopes are a robust proxy for $\mathrm{pH}$, but the constrained estimation of $p \mathrm{CO}_{2}$ requires a second parameter of the carbonate system (Foster and Rae, 2016), which in turn requires additional assumptions. To independently test the validity of these assumptions, we have taken the TAlk values and $\left[\mathrm{CO}_{3}{ }^{2-}\right]$ values (converted to total alkalinity equivalents) used in the Cenozoic $\delta^{11} \mathrm{~B}$ based $\mathrm{pCO}_{2}$ compilation of Foster et al. (2017) and compared them to our independently modeled calculated TAlk records (Fig. 9a). Then, we recalculated these $\delta^{11} \mathrm{~B}$-based $p \mathrm{CO}_{2}$ estimates based on our new TAlk records (Fig. 9b) to see if this resulted in significant differences with respect to the original reconstructions. (These calculations were made with the $\mathrm{R}$ package seacarb, using modern values for the thermodynamic constants $K_{0}, K_{1}$ and $K_{2}$, and using temperature and salinity values as reported in the original publications.)
Our model TAlk values agree with those used in $\delta^{11} \mathrm{~B}$-based $p \mathrm{CO}_{2}$ reconstructions (Fig. 9a) and consequently, the differences between published $p \mathrm{CO}_{2}$ values and recalculated $\mathrm{pCO}_{2}$ values (Fig. 9B) are small for most of the Cenozoic. For the Pleistocene and Pliocene, all $p \mathrm{CO}_{2}$ values are comparable within their respective errors, but for the Miocene, our model actually offers slightly higher alkalinity values and hence $p \mathrm{CO}_{2}$ values, i.e., elevated by approximately 50-100 ppmv. Further back in time, more significant differences become apparent. For the Eocene, our retrodicted CAlk record generally yields much lower $p \mathrm{CO}_{2}$ values than the published values, with a dramatic difference of more than 500 ppmv for the early Eocene at $\sim 53 \mathrm{Ma}$, much more consistent with the secular trend in Beerling and Royer (2011) - see Fig. 2a. If these recalculated $p \mathrm{CO}_{2}$ estimates are to be taken at face value, average early Eocene $\mathrm{CO}_{2}$ concentrations may have been much lower and more stable than inferred by Anagnostou et al. (2016). If anything, this major difference highlights the fundamental challenges in understanding the evolution of ocean carbonate chemistry under early Eocene greenhouse climates. We suggest that our retrodicted TAlk record can be used as a new framework for future $\mathrm{pCO}_{2}$ reconstructions and that future studies should focus on reconciling the mismatch between a shallow $\mathrm{CCD}$ and very high $\mathrm{CO}_{2}$ concentrations.

\section{Conclusions}

The secular state and variations of the carbonate system chemistry of the oceans can be retrodicted with a relatively simple, data-driven, inverse model, using available atmospheric $\mathrm{CO}_{2}$ 
records, e.g., Beerling and Royer (2011) or the database at http:// www.p-co2.org/data/, the carbonate ion record from Boudreau and Luo (2017), and the dissolved calcium and magnesium records in Hain et al. (2015), and a small number of justified assumptions. Our model provides an excellent retrodiction of the Boron-based $\mathrm{pH}$ of the surface waters of the Cenozoic seas, supplying some degree of confidence in our results. We also employed our results to recalculate the atmospheric $p \mathrm{CO}_{2}$ record from Boron isotopes and showed that our retrodictions agree well with past estimates after $45 \mathrm{Ma}$, but that between 45 and $55 \mathrm{Ma}$, our estimates are far lower than reported in other studies.

The retrodictions of the CAlk and DIC of the oceans are almost identical when driven by either the Lyle et al. (2008), or the Pälike et al. (2012) CCD records, or as modified by the Leon-Rodriguez and Dickens (2010) data. Nevertheless, the causes of the variations in these records are decidedly different in the later Cenozoic (last $\sim 15 \mathrm{Ma}$ ). In this interval, the Lyle et al.-based model links CAlk and DIC changes to changes in the alkalinity input $\left(F_{O}\right)$ to the pelagic oceans, while the Pälike et al.-based model drives the CAlk and DIC variations with changes in atmospheric $\mathrm{CO}_{2}$ and changing values of the thermodynamic constants of the carbonate system with a general cooling of the oceans, which is a radically different explanation.

Assumptions used in past models, e.g., constant surface alkalinity, constant surface saturation, and constant $\left[\mathrm{CO}_{3}{ }^{2-}\right]_{\mathrm{S}}$ to $\left[\mathrm{CO}_{3}{ }^{2-}\right]_{\mathrm{D}}$ ratio, are not reproduced by our model; this does not invalidate these past assumptions, but it certainly means that their adoption requires justification, as do our own.

We offer one final caveat, which is true of all model studies: if new data is later found to disagree with our retrodictions, this may indicate that one or more of our assumptions is wrong, e.g., ignoring OC-oxidation-driven dissolution in pelagic sediments and the resulting one-to-one alkalinity to DIC flux.

\section{Acknowledgements}

BPB gratefully acknowledges funding from the Natural Sciences and Engineering Research Council of Canada. JJM, AS, and R.v.d.P. were supported by the Netherlands Earth System Science Center (NESSC), as was a sabbatical stay in Utrecht by BPB. We thank Dr. Jeremy Caves-Rugenstein (ETH) and two other anonymous reviewers, as well as our Editor (JA), for their thought provoking and challenging comments; hopefully we have adequately addressed them so that a future reader will also be satisfied with our exposition of this problem.

\section{Appendix A. Supplementary material}

Supplementary material related to this article can be found online at https://doi.org/10.1016/j.epsl.2019.02.004.

\section{References}

Anagnostou, E.E., John, E.H., Edgar, K.M., Foster, G.L., Ridgwell, A., Inglis, G.N., Pancost, R.D., Lunt, D.J., Pearson, P.N., 2016. Changing atmospheric $\mathrm{CO}_{2}$ concentration was the primary driver of early Cenozoic climate. Nature 533, 380-384. https://doi.org/10.1038/nature17423.

Arvidson, R.S., Mackenzie, F.T., Guidry, M., 2006. MAGic: a Phanerozoic model for the geochemical cycling of major rock-forming components. Am. J. Sci. 306 135-190.

Beerling, D.J., Royer, D.L., 2011. Convergent Cenozoic $\mathrm{CO}_{2}$ history. Nat. Geosci. 4, 418-420. https://doi.org/10.1038/ngeo1186.

Berger, W.H., Herguera, J.C., 1992. Reading the sedimentary record of the ocean's productivity. In: Falkowski, P.G., Woodhead, A.D. (Eds.), Primary Productivity and Biogeochemical Cycles in the Sea. Plenum Press, New York, pp. 455-486.

Berner, E.K., Berner, R.A., 2012. Global Environment: Water, Air and Geochemical Cycles. Princeton University Press. 444 pp.

Berner, R.A., 2006. GEOCARBSULF: a combined model for Phanerozoic atmospheric $\mathrm{O}_{2}$ and $\mathrm{CO}_{2}$. Geochim. Cosmochim. Acta 70, 5653-5664.
Berner, R.A., Lasaga, A.C., Garrels, R.M., 1983. The carbonate-silicate geochemical cycle and its effects on atmospheric carbon dioxide over the past 100 million years. Am. J. Sci. 283, 641-683.

Bice, K.L., Marotzke, J., 2001. Numerical evidence against reversed thermohaline circulation in the warm Paleocene/Eocene ocean. J. Geophys. Res. 106, $11529-11542$

Boudreau, B.P., Luo, L., 2017. Retrodiction of secular variations in deep-sea $\mathrm{CaCO}_{3}$ burial during the Cenozoic. Earth Planet. Sci. Lett., 1-12. https://doi.org/10.1016/ j.epsl.2017.06.005.

Boudreau, B.P., Middelburg, J.J., Hofmann, A.F., Meysman, F.J.R., 2010. Ongoing transients in carbonate compensation. Glob. Biogeochem. Cycles 24, GB4010. https:// doi.org/10.1029/2009GB003654.

Broecker, W.S., Lynch-Stieglitz, J., Archer, D., Hofmann, M., Maier-Reimer, E., Marchal, O., Stocker, T., Gruber, N., 1999. How strong is the Harvardton-Bear constraint? Glob. Biogeochem. Cycles 13, 817-820. https://doi.org/10.1029/1999GB900050.

Broecker, W.S., Peng, T-H., 1982. Tracers in the Sea. Lamont-Doherty Geological Observatory. Columbia University, New York.

Caldeira, K., Rampino, M.R., 1993. Aftermath of the end-Cretaceous mass extinction: possible biogeochemical stabilization of the carbon cycle and climate. Paleoceanography 8, 515-525. https://doi.org/10.1029/93PA01163.

Caves, J.K., Jost, A.B., Lau, K.V., Maher, K., 2016. Cenozoic carbon cycle imbalances and a variable weathering feedback. Earth Planet. Sci. Lett. 450, 152-163. https://doi.org/10.1016/j.epsl.2016.06.035.

Emerson, S., Bender, M., 1981. Carbon fluxes at the sediment-water interface of the deep-sea: calcium carbonate preservation. J. Mar. Res. 39, 139-162.

Feely, R.A., Sabine, C.L., Lee, K., Berelson, W., Kleypas, J., Fabry, V.J., Millero, F.J., 2004. Impact of anthropogenic $\mathrm{CO}_{2}$ on the $\mathrm{CaCO}_{3}$ system of the oceans. Science 305, 362-366.

Fiadeiro, M.M., 1980. The alkalinity of the deep Pacific. Earth Planet. Sci. Lett. 49, 499-505. https://doi.org/10.1016/0012-821X(80)90090-4. http://www. sciencedirect.com/science/article/pii/0012821X80900904.

Foster, G.L., 2008. Seawater pH, $\mathrm{pCO}_{2}$ and $\left[\mathrm{CO}_{3}{ }^{2-}\right]$ variations in the Caribbean Sea over the last $130 \mathrm{kyr}$ : a boron isotope and $\mathrm{B} / \mathrm{Ca}$ study of planktic foraminifera. Earth Planet. Sci. Lett. 271, 254-266. https://doi.org/10.1016/j.epsl.2008.04.015.

Foster, G.L., Rae, J.W.B., 2016. Reconstructing ocean pH with Boron isotopes in foraminifera. Annu. Rev. Earth Planet. Sci. 44, 207-237.

Foster, G.L., Royer, D.L., Lunt, D.J., 2017. Future climate forcing potentially without precedent in the last 420 million years. Nat. Commun. 8, 14845. https://doi.org/ $10.1038 /$ ncomms 14845. See Supplementary Information.

Hain, M.P., Sigman, D.M., Higgins, J.A., Haug, G.H., 2015. The effects of secular calcium and magnesium concentration changes on the thermodynamics of seawater acid/base chemistry: implications for Eocene and Cretaceous ocean carbon chemistry and buffering. Glob. Biogeochem. Cycles 29. https://doi.org/10.1002/ 2014 GB004986.

Hansen, J., Sato, M., Russell, G., Kharecha, P., 2013. Climate sensitivity, sea level and atmospheric carbon dioxide. Philos. Trans. R. Soc. Lond. A 371, 20120294. https://doi.org/10.1098/rsta.2012.0294.

Heinze, M., Ilyina, T., 2015. Ocean biogeochemistry in the warm climate of the late Paleocene. Clim. Past 11, 63-79. https://doi.org/10.5194/cp-11-63-2015.

Hilting, A.K., Kump, L.R., Bralower, T.J., 2008. Variations in the oceanic vertical carbon isotope gradient and their implications for the Paleocene-Eocene biological pump. Paleoceanography 23, PA3222. https://doi.org/10.1029/2007PA001458.

Hönisch, B., Hemming, N.G., 2005. Surface ocean pH response to variations in $\mathrm{pCO}_{2}$ through two full glacial cycles. Earth Planet. Sci. Lett. 236 (1-2), 305-314. https://doi.org/10.1016/j.epsl.2005.04.027.

Hönisch, B., Hemming, N.G., Archer, D., Siddall, M., McManus, J.F., 2009. Atmospheric carbon dioxide concentration across the mid-Pleistocene transition. Science 324, 1551-1554.

Hülse, D., Arndt, S., Wolson, J.D., Mulhoven, G., Ridgwell, A., 2017. Understanding the causes and consequences of past marine carbon cycling variability through models. Earth-Sci. Rev. 171, 349-382. https://doi.org/10.1016/j.earscirev.2017.06. 004

Jahnke, R.A., Craven, D.B., Gaillard, J.-F., 1994. The influence of organic matter diagenesis on $\mathrm{CaCO}_{3}$ dissolution at the deep-sea floor. Geochim. Cosmochim. Acta 58, 2799-2809.

Jahnke, R.A., Jahnke, D.B., 2004. Calcium carbonate dissolution in deep sea sediments: reconciling microelectrode, pore water and benthic flux chamber results. Geochim. Cosmochim. Acta 68, 47-59.

Leon-Rodriguez, L., Dickens, G., 2010. Constraints on ocean acidification associated with rapid and massive carbon injections: the early Paleogene record at ocean drilling program site 1215, equatorial Pacific Ocean. Palaeogeogr. Palaeoclimatol. Palaeoecol. 298, 409-420. https://doi.org/10.1016/j.palaeo.2010.10.029.

Lyle, M., Barron, J., Bralower, T.J., Huber, M., Lyle, A.O., Ravelo, A.C., Rea, D.K., Wilson, P.A., 2008. Pacific Ocean and Cenozoic evolution of climate. Rev. Geophys. 46, RG2002. https://doi.org/10.1029/2005RG000190.

Keir, R.S., 1988. On the late Pleistocene ocean geochemistry and circulation. Paleoceanography 3, 413-445. https://doi.org/10.1029/PA003i004p00413.

Knox, F., McElroy, M.B., 1984. Changes in atmospheric $\mathrm{CO}_{2}$ : influence of the marine biota at high latitude. J. Geophys. Res. 89, 4629-4637. https://doi.org/10.1029/ JD089iD03p04629. 
Mackenzie, F.T., Ver, L.M., Sabine, C., Lane, M., 1993. C, N, P, S global biogeochemical cycles and modeling of global change. In: Wolast, R., Mackenzie, F.T., Chou, L. (Eds.), Interactions of C, N, P, and S Biogeochemical Cycles and Global Change. In: NATO ASI Ser., vol. 14, pp. 1-61.

Maier-Reimer, E.E., 1993. Geochemical cycles in an ocean general circulation model. Preindustrial tracer distributions. Glob. Biogeochem. Cycles 7, 645-677. https:// doi.org/10.1029/93GB01355.

Milliman, J.D., 1993. Production and accumulation of calcium carbonate in the ocean: budget of a nonsteady state. Glob. Biogeochem. Cycles 7, 927-957. https://doi.org/10.1029/93GB02524.

Milliman, J.D., Troy, P.J., Balch, W.M., Adams, A.K., Li, Y.H., Mackenzie, F.T., 1999. Biologically mediated dissolution of calcium carbonate above the chemical lysocline? Deep-Sea Res., Part 1, Oceanogr. Res. Pap. 46, 1653-1669. https:// doi.org/10.1016/S0967-0637(99)00034-5.

Misra, S., Froelich, P.N., 2012. Lithium isotope history of Cenozoic seawater: changes in silicate weathering and reverse weathering. Science 335, 818-823. https:// doi.org/10.1126/science.

Nir, O., Vengoshb, A., Harknessb, J.S., Dwyerb, G.S., Lahav, O., 2015. Direct measurement of the Boron isotope fractionation factor: reducing the uncertainty in reconstructing ocean paleo-pH. Earth Planet. Sci. Lett. 414, 1-5. https:// doi.org/10.1016/j.epsl.2015.01.006.

Omta, A.W., van Voorn, G.A.K., Rickaby, R.E.M., Follows, M.J., 2013. On the potential role of marine calcifiers in glacial-interglacial dynamics. Glob. Biogeochem. Cycles 27, 692-704. https://doi.org/10.1002/gbc.20060.

Pälike, H., Lyle, M.W., Nishi, H., Raffi, I., Ridgwell, A., Gamage, K., Klaus, A., Acton, G.D., Anderson, L., Backman, J., Baldauf, J.G., Beltran, C., Bohaty, S.M., Bown, P.R., Busch, W.H., Channell, J.E.T., Chun, C.O.J., Delaney, M.L., Dewang, P., Dunkley Jones, T., Edgar, K.M., Evans, H.F., Fitch, P., Foster, G.L., Gussone, N., Hasegawa, H., Hathorne, E., Hayashi, H., Herrle, J.O., Holbourn, A., Hovan, S.A., Hyeong, K., Iijima, K., Ito, T., Kamikuri, S.-I., Kimoto, K., Kuroda, J., LeonRodriguez, L., Malinverno, A., Moore, T.C., Murphy, B., Murphy, D.P., Nakamur H., Ogane, K., Ohneiser, C., Richter, C., Robinson, R.S., Rohling, E.J., Romero, O.E., Sawada, K., Scher, H.D., Schneider, L., Sluijs, A., Takata, H., Tian, J., Tsujimoto, A., Wade, B.S., Westerhold, T., Wilkens, R.H., Williams, T., Wilson, P.A., Yamamoto, Y., Yamamoto, S., Yamazaki, T., Zeebe, R.E., 2012. A Cenozoic record of the equatorial Pacific carbonate compensation depth. Nature 488, 609-614. https://doi.org/10.1038/nature113360.

Palmer, M.R., Pearson, P.N., 2003. A 23,000-year record of surface water pH and $\mathrm{pCO}_{2}$ in the Western Equatorial Pacific Ocean. Sci. Express 300, 480-482. http:// www.sciencexpress.org/27March2003/Page1/10.1126/science.1080796.

Palmer, M.R., Pearson, P.N., Cobb, S.J., 1998. Reconstructing past ocean pH-depth profiles. Science 282, 1468-1471.

Pearson, P.N., Palmer, M.R., 2000. Atmospheric carbon dioxide concentrations over the past 60 million years. Nature 406, 695-699.

Raymo, M.E., Ruddiman, W.F., 1992. Tectonic forcing of late Cenozoic climate. Nature 359, 117-122. https://doi.org/10.1038/359117a0.

Ridgwell, A., Hargreaves, J.C., 2007. Regulation of atmospheric $\mathrm{CO}_{2}$ by deep-sea sediments in an Earth system model. Glob. Biogeochem. Cycles 21, GB2008. https:// doi.org/10.1029/2006GB002764.

Ridgwell, A.J., Kennedy, M.J., Caldeira, K., 2003. Carbonate deposition, climate stability, and Neoproterozoic Ice Ages. Science 302, 859-862.
Sabine, C.L., Feely, R.A., Key, R.M., Bullister, J.L., Millero, F.J., Lee, K., Peng, T.-H. Tilbrook, B., Ono, T., Wong, C.S., 2002. Distribution of anthropogenic $\mathrm{CO}_{2}$ in the Pacific Ocean. Glob. Biogeochem. Cycles 16, 1083. https://doi.org/10.1029/ 2001GB001639.

Sarmiento, J.L., Gruber, N., 2006. Ocean Biogeochemical Dynamics. Princeton University Press, Princeton. 503 pp.

Sarmiento, J.L., Toggweiler, J.R., 1984. A new model for the role of the oceans in determining atmospheric $\mathrm{pCO}_{2}$. Nature 308, 621-624. https://doi.org/10.1038/ $308621 \mathrm{a} 0$.

Siegenthaler, U., Wenk, T., 1984. Rapid atmospheric $\mathrm{CO}_{2}$ variations and ocean circulation. Nature 308, 624-626. https://doi.org/10.1038/308624a0.

Sigman, D.M., Boyle, E.A., 2000. Glacial/interglacial variations in atmospheric carbon dioxide. Nature 407, 859-869.

Slotnick, B.S., Lauretano, V., Backman, J., Dickens, G.R., Sluijs, A., Loutens, L., 2015. Early Paleogene variations in the calcite compensation depth: new constraints using old borehole sediments from across Ninetyeast Ridge, central Indian Ocean. Clim. Past 11, 473-493.

Sosdian, S.M., Greenop, R., Hain, M.P., Foster, P.N., Lear, C.H., 2018. Constraining the evolution of Neogene ocean carbonate chemistry using the boron isotope $\mathrm{pH}$ proxy. Earth Planet. Sci. Lett. 498, 362-376. https://doi.org/10.1016/j.epsl.2018. 06.017.

Spivack, A.J., You, C.-F., Smith, J., 1993. Foraminiferal Boron isotope ratios as a proxy for surface ocean pH over the past 21 Myr. Nature 363, 149-151.

Tyrrell, T., Zeebe, R.E., 2004. History of carbonate ion concentration over the last 100 million years. Geochim. Cosmochim. Acta 68, 3521-3530.

van Andel, T.H., 1975. Mesozoic/Cenozoic calcite compensation depth and the globa distribution of calcareous sediments. Earth Planet. Sci. Lett. 26, 187-194.

Vigier, N., Rollion-Bard, C., Leveson, Y., Erez, J., 2015. Lithium isotopes in foraminifera shells as a novel proxy for the ocean dissolved inorganic carbon (DIC). C. R. Geosci. 347, 43-51.

Wallmann, K., 2001. Controls on the Cretaceous and Cenozoic evolution of seawater composition, atmospheric $\mathrm{CO}_{2}$ and climate. Geochim. Cosmochim. Acta 65 3005-3025.

Winguth, C., Winguth, A.M.E., 2012. Simulating Permian-Triassic oceanic anoxia distribution: implications for species extinction and recovery. Geology 40, 127-130. https://doi.org/10.1130/G32453.1.

Yu, J., Elderfield, H., 2007. Benthic foraminiferal B/Ca ratios reflect deep water carbonate saturation state. Earth Planet. Sci. Lett. 258, 73-86. https://doi.org/10. 1016/j.epsl.2007.03.025.

Zeebe, R.E., 2012. LOSCAR: long-term ocean-atmosphere-sediment carbon cycle reservoir model v2.0.4. Geosci. Model Dev. 5, 149-166. https://doi.org/10.5194/ gmd-5-149-2012.

Zeebe, R.E., Tyrrell, T., 2018. Comment on "The effects of secular calcium and magnesium concentration changes on the thermodynamics of seawater acid/base chemistry: implications for Eocene and Cretaceous ocean carbon chemistry and buffering" by Hain et al. (2015). Glob. Biogeochem. Cycles 32, 895-897. https:// doi.org/10.1002/2017GB005786.

Zeebe, R.E., Zachos, J.C., 2007. Reversed deep-sea carbonate ion basin gradient during the Paleocene-Eocene thermal maximum. Paleoceanography 22, PA3201. https://doi.org/10.1029/2006PA001395. 